\title{
Tempol, a Superoxide Dismutase Mimetic Agent, Inhibits Superoxide Anion-Induced Inflammatory Pain in Mice
}

\author{
Catia C. F. Bernardy, ${ }^{1}$ Ana C. Zarpelon, ${ }^{2}$ Felipe A. Pinho-Ribeiro, ${ }^{2}$ \\ Cássia Calixto-Campos, ${ }^{2}$ Thacyana T. Carvalho, ${ }^{2}$ Victor Fattori, ${ }^{2}$ Sergio M. Borghi, ${ }^{2}$ \\ Rubia Casagrande, ${ }^{3}$ and Waldiceu A. Verri Jr. ${ }^{2}$ \\ ${ }^{1}$ Department of Nursing, Health Science Centre, State University of Londrina, Londrina, PR, Brazil \\ ${ }^{2}$ Department of Pathology, Biological Science Centre, State University of Londrina, Londrina, PR, Brazil \\ ${ }^{3}$ Department of Pharmaceutical Sciences, Health Science Centre, State University of Londrina, Londrina, PR, Brazil
}

Correspondence should be addressed to Waldiceu A. Verri Jr.; waldiceujr@yahoo.com.br

Received 29 December 2016; Revised 26 March 2017; Accepted 12 April 2017; Published 14 May 2017

Academic Editor: Vickram Ramkumar

Copyright (C) 2017 Catia C. F. Bernardy et al. This is an open access article distributed under the Creative Commons Attribution License, which permits unrestricted use, distribution, and reproduction in any medium, provided the original work is properly cited.

\begin{abstract}
The present study evaluated the anti-inflammatory and analgesic effects of the superoxide dismutase mimetic agent tempol in superoxide anion-induced pain and inflammation. Mice were treated intraperitoneally with tempol (10-100 mg/kg) $40 \mathrm{~min}$ before the intraplantar injection of a superoxide anion donor, potassium superoxide $\left(\mathrm{KO}_{2}, 30 \mu \mathrm{g}\right)$. Mechanical hyperalgesia and thermal hyperalgesia, paw edema, and mRNA expression of peripheral and spinal cord mediators involved in inflammatory pain, TNF $\alpha$, IL$1 \beta$, IL-10, COX-2, preproET-1, gp91 ${ }^{\text {phox }}$, Nrf2, GFAP, and Iba-1, were evaluated. Peripheral and spinal cord reductions of antioxidant defenses and superoxide anion were also assessed. Tempol reduced $\mathrm{KO}_{2}$-induced mechanical hyperalgesia and thermal hyperalgesia and paw edema. The increased mRNA expression of the evaluated mediators and oxidative stress in the paw skin and spinal cord and increased mRNA expression of glial markers in the spinal cord induced by $\mathrm{KO}_{2}$ were successfully inhibited by tempol. $\mathrm{KO}_{2}$-induced reduction in Nrf2 mRNA expression in paw skin and spinal cord was also reverted by tempol. Corroborating the effect of tempol in the $\mathrm{KO}_{2}$ model, tempol also inhibited carrageenan and CFA inflammatory hyperalgesia. The present study demonstrates that tempol inhibits superoxide anion-induced molecular and behavioral alterations, indicating that tempol deserves further preclinical studies as a promising analgesic and anti-inflammatory molecule for the treatment of inflammatory pain.
\end{abstract}

\section{Introduction}

Superoxide dismutase (SOD) is an antioxidant enzyme that regulates the levels of reactive oxygen species such as superoxide anion $\left(\mathrm{O}_{2}{ }^{-}\right)$under basal conditions in tissue metabolism and health [1, 2]. However, reactive oxygen species may shatter healthy tissues by itself or through interactions with other molecules such as nitric oxide (NO) in inflammation. During inflammatory reactions, free radicals are produced at rates which overwhelm the endogenous antioxidant capacity, making the tissues vulnerable to injuries.

Superoxide anion is the initial product of oxygen reduction and its inhibition represents an important step to prevent the deleterious events related to oxidative stress $[3,4]$. After tissue injury and/or infections, neutrophils are initially recruited following inflammatory and chemotactic signals, which include the inflammatory cytokines interleukin-1 beta (IL-1 $\beta$ ) and tumor necrosis factor (TNF) [5] as well as reactive oxygen species themselves [6]. After being recruited into the inflammatory focus, neutrophils are activated by these signals, including the activation of the socalled respiratory burst represented by the nicotinamide adenine dinucleotide phosphate (NADPH) oxidase membranebound enzyme complex production of superoxide anion in neutrophils. This scenario characterized by the exacerbation of superoxide anion production propagates the inflammatory response resulting in sensitization of primary nociceptive 
neurons [7]. The terminal endings of nociceptive neurons are widespread in all tissues, where they identify noxious (intense) stimuli, including trauma, chemicals, heat, and cold. In fact, reactive oxygen species and cytokines sensitize and activate nociceptive neurons during the inflammatory response [8-10]. Interestingly, the nociceptive transmission is enhanced by reactive oxygen and nitrogen species not only at the site of initial injury, but also at the spinal cord level in response to increased nociceptive transmission after a peripheral injury [1]. In this sense, targeting superoxide anion and its downstream effectors at peripheral and central sites is a promising approach to inhibit inflammatory pain.

Tempol (4-hydroxy-2,2,6,6-tetramethylpiperidine- $N$ oxyl) is a redox-cycling nitroxide water-soluble SOD mimetic agent. Due to its low molecular weight, tempol passes through biological membranes [11]. Tempol favors the metabolism of a wide variety of cellular reactive oxygen and nitrogen species and reduces oxidative stress. Thus, tempol is a potent antioxidant [12]. The beneficial biological effects of tempol range from protective effects against radiation, metabolic syndrome, and shock as well as heart, kidney, and central nervous system safekeeping [12]. Tempol inhibits superoxide anion-induced neuronal firing, thermal hyperalgesia, and edema induced by carrageenan, neuropathic pain induced by chronic constriction injury (CCI) [13-15] and chemotherapy [16] in rats, and $\mathrm{TNF} \alpha$-induced mechanical hyperalgesia and neutrophils recruitment in mice [7]. Tempol treatment also eliminates free radicals and inhibits lipid peroxidation in vitro and in vivo $[15,17-19]$. However, the literature lacks a proof-of-concept demonstration that tempol inhibits superoxide anion-triggered pain and inflammation.

In the present study, the effects of SOD mimetic agent tempol were evaluated in a model of superoxide anion donor (potassium superoxide; $\mathrm{KO}_{2}$ )-induced pain and inflammation in mice.

\section{Methods}

2.1. Animals. The experiments were performed on male Balb/c mice (20-25 g) housed in standard plastic cages with free access to food and water. All behavioral testing was performed between 9:00 am and 5:00 pm in a temperatureand light-controlled room. Animals' care and handling procedures were in accordance with the International Association for Study of Pain (IASP) guidelines and with the approval of the Ethics Committee of State University of Londrina (process 7706.2013-42). Mice were used only once and were acclimatized to the testing room at least 1 hour before the experiments. At the end of experiments, mice were anesthetized with isoflurane $3 \%$ to minimize suffering (Abbott Park, IL, USA) and terminally killed by cervical dislocation followed by decapitation. Animals were monitored periodically at indicated time points during the experiments. No unexpected animal deaths occurred during this study. All efforts were made to minimize the number of animals used and their suffering.

2.2. Drugs and Reagents. Drugs and reagents used in the study were obtained from the following sources: Potassium superoxide $\left(\mathrm{KO}_{2}\right)$ 96.5\% was purchased from Alfa Aesar (Ward Hill, MA, USA); 4-hydrophosphinyloxy TEMPO, triethylammonium salt (tempol) 99\%, and carrageenan were purchased from Santa Cruz Biotechnology (Santa Cruz, CA, USA); nitroblue tetrazolium (NBT) was purchased from Amresco (Solon, OH, USA); complete Freund's adjuvant (CFA), ferric chloride hexahydrate, 2,4,6-tripyridyl-s-triazine (TPTZ), and ABTS [2,20-azino-bis(3-ethylbenzothiazoline6-sulfonate)] were purchased from Sigma-Aldrich (St. Louis, MO, USA).

2.3. Experimental Protocols. Mice were treated intraperitoneally (i.p.) with vehicle (sterile saline, $100 \mu \mathrm{L}$, i.p.) or tempol (10-100 mg/kg and $100 \mathrm{mg} / \mathrm{kg}, 100 \mu \mathrm{L}$, i.p.) and after 40 min received intraplantar (i.pl.) injection of vehicle (control group, saline, $25 \mu \mathrm{L}$ ) or $\mathrm{KO}_{2}(30 \mu \mathrm{g}, 25 \mu \mathrm{L})$. Mechanical hyperalgesia and thermal hyperalgesia and paw edema measurements were performed between 1 and $5 \mathrm{~h}$ after $\mathrm{KO}_{2}$ injection. Cytokines (TNF $\alpha$, pro-IL-1 $\beta$, and IL10), cyclooxygenase-2 (COX-2), and preproendothelin-1 (preproET-1) mRNA expressions were determined in paw tissue and spinal cord (L4-L6) samples $3 \mathrm{~h}$ after $\mathrm{KO}_{2}$ or vehicle injection. Following the same protocol, antioxidant capacity was evaluated by the ferric reducing ability of plasma (FRAP), ABTS, and glutathione reduced (GSH) levels assay and oxidative stress was evaluated by superoxide anion production (NBT reduction assay) assay in the paw skin and spinal cord tissues. The gp $91^{\text {phox }}$ and nuclear factor erythroid 2-related factor (Nrf2) mRNA expressions were evaluated in the paw skin and spinal cord tissues. Glial fibrillary acidic protein (GFAP) and ionized calcium binding adaptor molecule 1 (Iba-1) mRNA expressions were determined in spinal cord samples. In another experiment, mice were treated intraperitoneally (i.p.) with vehicle (sterile saline, $100 \mu \mathrm{L}$, i.p.) or tempol (100 mg/kg and $100 \mathrm{mg} / \mathrm{kg}, 100 \mu \mathrm{L}$, i.p.) and after $40 \mathrm{~min}$ received intraplantar (i.pl.) injection of vehicle (control group, saline, $25 \mu \mathrm{L}$ ) or carrageenan $(300 \mu \mathrm{g}$, $25 \mu \mathrm{L}$ ), respectively. Mechanical hyperalgesia and thermal hyperalgesia measurements were performed between 1 and $5 \mathrm{~h}$ after carrageenan injection. In a prolonged inflammation model, vehicle or tempol treatment $(100 \mathrm{mg} / \mathrm{kg}, 100 \mu \mathrm{L}$, i.p.) was given daily starting one day after CFA $(10 \mu \mathrm{L})$ i.pl. injection, and mechanical hyperalgesia and thermal hyperalgesia were evaluated always $30 \mathrm{~min}$ after treatment from 1 to 7 days. The dose of carrageenan, CFA, and $\mathrm{KO}_{2}$ and time points chosen for the experimental protocol were determined according to previous studies of our laboratory $[7,20-23]$.

2.4. Electronic Pressure Meter Test for Mechanical Hyperalgesia Measurement. The test consisted of evoking a hindpaw reflex with a handheld force transducer (Electronic von Frey Anesthesiometer; Insight, Ribeirão Preto, SP, Brazil) adapted with a $0.5 \mathrm{~mm}^{2}$ polypropylene tip. Detailed methodology was previously described [24]. The results are expressed by delta $(\Delta)$ of withdrawal threshold (in g) calculated by subtracting the measurements at the indicated time points after stimulus injection from the basal measurements. 
2.5. Hot Plate Test. The test was performed as reported previously [25]. Briefly, mice were placed the hot plate apparatus (EFF 361, Insight Equipamentos, Ribeirão Preto, SP, Brazil) maintained at $55^{\circ} \mathrm{C}$. The reaction time was scored when hindpaw licking or flinching occurred in the injected paw and/or mice jumped. As the basal latencies were always smaller than $20 \mathrm{~s}$ (between 15 and $18 \mathrm{~s}$ ), a maximum latency (cut-off) was set at $20 \mathrm{~s}$ to avoid tissue damage.

2.6. Paw Edema. The paw edema formation was measured using a caliper (Digimatic Caliper, Mitutoyo Corporation, Kanagawa, Japan). Values of paw thickness are expressed as the difference $(\Delta \mathrm{mm})$ between the values obtained just before (basal) and after stimulus injection.

\subsection{Reverse Transcriptase and Quantitative Polymerase Chain} Reaction (RT-qPCR). Paw skin and spinal cord tissue samples were collected $3 \mathrm{~h}$ after $\mathrm{KO}_{2}$ or vehicle injection and homogenized in TRIzol ${ }^{\circledR}$ reagent. The total RNA was extracted using the SV Total RNA Isolation System (Promega Biosciences, Fitchburg, WI, USA). RT-PCR and quantitative PCR were performed using GoTaq ${ }^{\circledR}$ 2-Step RT-qPCR System (Promega) following the manufacturer's directions. Complementary DNA was reverse-transcribed from $2 \mu \mathrm{g}$ of total RNA, and quantitative PCR was performed on a LightCycler $^{\circledR}$ Nano Instrument (Roche). The following primer sequences were used: TNF $\alpha$ : sense, $5^{\prime}$-TCTCATCAGTTCTATGGCCC- $3^{\prime}$, antisense, $5^{\prime}$-GGGAGTAGACAAGGTACAAC- $3^{\prime}$; pro-IL- $1 \beta$ : sense, $5^{\prime}$-GAAATGCCACCTTTTGACAGTG-3', antisense, $5^{\prime}$-TGGATGCTCTCATCAGGACAG-3'; IL-10: sense, $5^{\prime}$-TCTCATCAGTTCTATGGCCC$3^{\prime}$; antisense, $5^{\prime}$-GGGAGTAGACAAGGTACAAC- $3^{\prime}$; COX2: sense, $5^{\prime}$-GTGGAAAAACCTCGTCCAGA-3', antisense, $5^{\prime}$-GCTCGGCTTCCAGTATTGAG-3'; preproET-1: sense, $5^{\prime}$-TGTGTCTACTTCTGCCACCT-3', antisense, $5^{\prime}$-CACCAGCTGCTGATAGATAC-3'; gp $91^{\text {phox }}$ : sense, $5^{\prime}$-AGCTATGAGGTGGTGATGTTAGTGG-3' , antisense, $5^{\prime}$-CACAATATTTGTACCAGACAGACTTGAG-3'; Nrf2: sense, $5^{\prime}$-TCACACGAGATGAGCTTAGGGCAA-3', antisense, 5'-TACAGTTCTGGGCGGCGACTTTAT-3'; GFAP: sense, $5^{\prime}$-GGCGCTCAATGCTGGCTTCA-3', antisense, $5^{\prime}$-TCTGCCTCCAGCCTCAGGTT-3' ; Iba-1: sense, $5^{\prime}$-ATGGAGTTTGATCTGAATGGAAAT- $3^{\prime}$, antisense, $5^{\prime}$-TCAGGGCAGCTCGGAGATAGCTTT-3' ${ }^{\prime}$; and GAPDH: sense, $5^{\prime}$ CATACCAGGAAATGAGCTTG-3', antisense, 5'-ATGACATCAAGAAGGTGGTG-3' . The expression of GAPDH mRNA was used as a reference gene to normalize data.

2.8. FRAP Assay. Mice were euthanized and samples of paw skin tissue and spinal cord were collected $3 \mathrm{~h}$ after $\mathrm{KO}_{2}$ or vehicle injection. The ability of paw skin and spinal cord tissues to reduce ferric ion was determined by FRAP assay $[26,27]$. The samples $(30 \mathrm{mg})$ were homogenized in $500 \mu \mathrm{L}$ of $\mathrm{KCl}(1.15 \%)$ using a Tissue-Tearor (BioSpec Products, Bartlesville, OK, USA) and centrifuged $\left(1.000 \mathrm{~g}, 10 \mathrm{~min}, 4^{\circ} \mathrm{C}\right)$, and the supernatant was used to measure the antioxidant capacity of samples. The supernatant $(30 \mu \mathrm{L})$ was mixed with the FRAP reagent $(0.3 \mathrm{mM}$ acetate buffer $\mathrm{pH} 3.6,10 \mathrm{mM}$
TPTZ in $40 \mathrm{mM}$ hydrochloride acid, and $20 \mathrm{mM}$ ferric chloride) and incubated at $37^{\circ} \mathrm{C}$ for $30 \mathrm{~min}$. The absorbance was determined in $595 \mathrm{~nm}$ (Multiskan GO, Thermo Fischer Scientific, Vantaa, Finland). Previously, a curve of Trolox was prepared and the results are presented as nanomoles of Trolox equivalent per milligram of tissue.

2.9. ABTS Assay. Mice were euthanized and tissue samples of paw skin and spinal cord were collected $3 \mathrm{~h}$ after $\mathrm{KO}_{2}$ or vehicle injection. The ability of samples to resist oxidative damage was determined by their ability to scavenge the ABTS radical. The supernatant was prepared as for the measurement of the antioxidant capacity in the FRAP assay. The ABTS solution was prepared with $7 \mathrm{mM}$ of ABTS and $2.45 \mathrm{mM}$ of potassium persulfate diluted with phosphate buffer pH 7.4 to absorbance of $0.7-0.8$ in $730 \mathrm{~nm}$. Then, the supernatant was mixed with ABTS solution and after $6 \mathrm{~min}$ the absorbance was determined in $730 \mathrm{~nm}$ (Multiskan GO, Thermo Fischer Scientific, Vantaa, Finland) [26, 27]. A curve of Trolox was prepared and the results are presented as nanomoles of Trolox equivalent per milligram of tissue.

2.10. GSH Assay. Paw skin and spinal cord samples of mice were collected $3 \mathrm{~h}$ after $\mathrm{KO}_{2}$ or vehicle injection and homogenized in ethylenediaminetetraacetic acid (EDTA) $0.02 \mathrm{M}$ and homogenates treated with $2 \mathrm{~mL} \mathrm{H}_{2} \mathrm{O}$ Milli Q plus $0.5 \mathrm{~mL}$ of trichloroacetic acid (TCA) $50 \%$. In the next step, homogenates were centrifuged $(1.500 \mathrm{~g}, 15 \mathrm{~min})$ and the resultant supernatant was added to $2 \mathrm{~mL}$ of a solution containing Tris $0.4 \mathrm{M}$ ( $\mathrm{pH} 8.9$ ) plus $50 \mathrm{~mL}$ of dithionitrobenzoic acid (DTNB). Then, after $5 \mathrm{~min}$, the measurements were performed using a spectrophotometer at $412 \mathrm{~nm}$ (Multiskan GO Microplate Spectrophotometer, Thermo Fischer Scientific, Vantaa, Finland) [27]. The results were presented as GSH (mmols per milligrams of tissue).

2.11. Superoxide Anion Production. Mice were euthanized and tissue samples of paw skin and spinal cord were collected $3 \mathrm{~h}$ after $\mathrm{KO}_{2}$ or vehicle injection. The measurement of superoxide anion production in tissue homogenates was performed using the NBT assay as described previously [28]. Briefly, $50 \mu \mathrm{L}$ of homogenates was incubated with $100 \mu \mathrm{L}$ of NBT $(1 \mathrm{mg} / \mathrm{ml})$ in 96 -well plate for $15 \mathrm{~min}$. The supernatant was then carefully removed and reduced formazan solubilized by adding $120 \mu \mathrm{L}$ of $\mathrm{KOH} 2 \mathrm{M}$ and $120 \mu \mathrm{L}$ of dimethylsulfoxide (DMSO). Reduction of NBT to formazan was measured at $600 \mathrm{~nm}$ using a microplate spectrophotometer reader (Multiskan GO, Thermo Fischer Scientific, Vantaa, Finland). The tissue weight was used for data normalization and the results are expressed as NBT reduction as optical density per mg of tissue.

2.12. Statistical Analysis. Results are presented as means \pm SEM of measurements made on 6 mice per group per experiment and are representative of 2 separate experiments. Two-way analysis of variance (ANOVA) was used to compare the groups and doses at all times (curves). The analyzed factors were treatments, time, and time versus treatment 


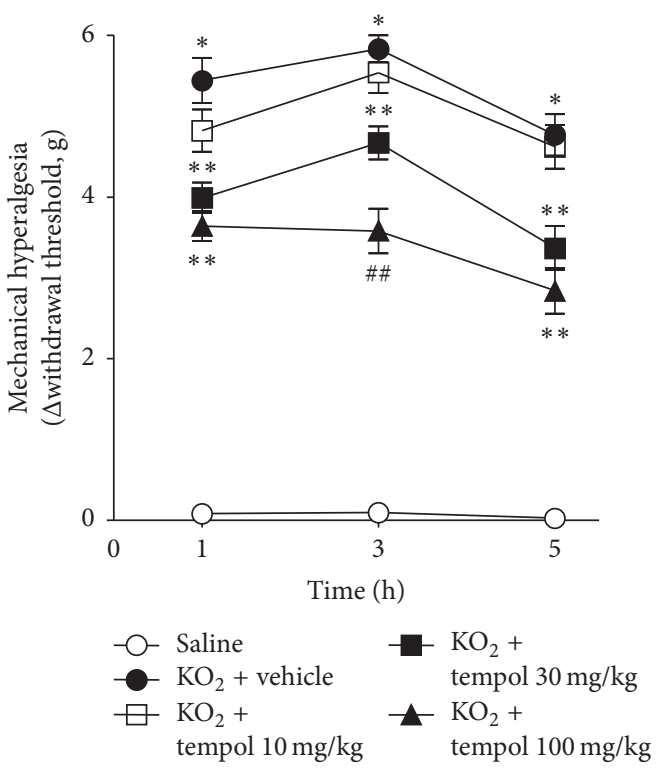

(a)

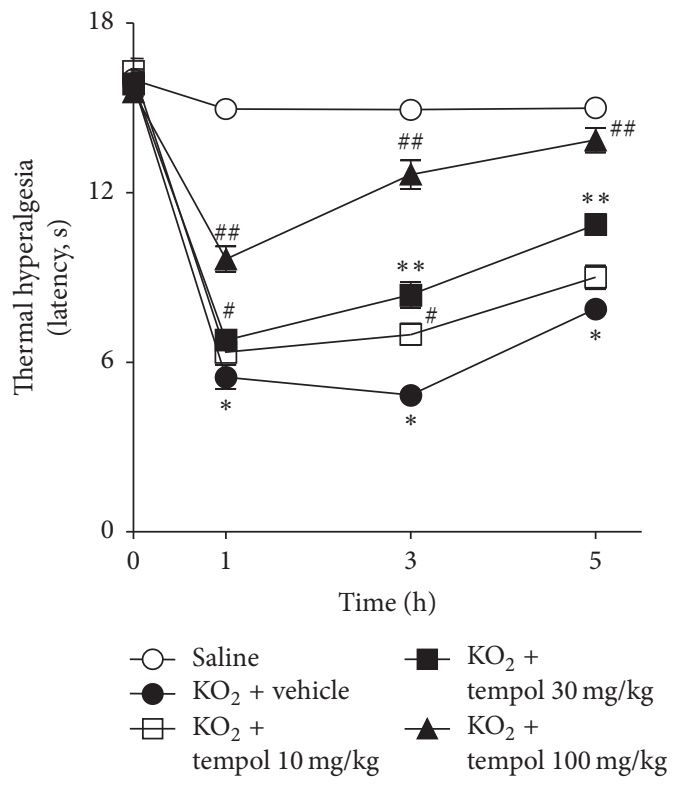

(b)

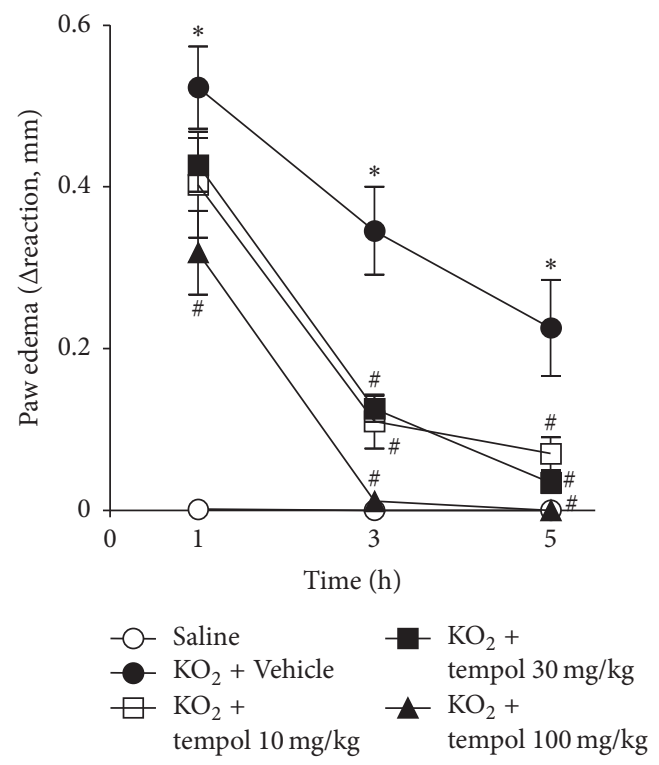

(c)

FIGURE 1: Tempol inhibits $\mathrm{KO}_{2}$-induced hyperalgesia and paw edema. Mice were treated with tempol (10-100 mg/kg) or vehicle $40 \mathrm{~min}$ before $\mathrm{KO}_{2}$ intraplantar injection. Nociceptive thresholds to mechanical (a) and thermal (b) stimuli as well as paw edema (c) were measured 1-5 $\mathrm{h}$ after $\mathrm{KO}_{2}$ injection. Results are expressed as means \pm SEM ( $n=6$ per group per experiment, representative of two separate experiments) $\left[{ }^{*} p<0.05\right.$ versus saline; ${ }^{\#} p<0.05$ versus $\mathrm{KO}_{2}+$ vehicle; ${ }^{* *} p<0.05$ versus $\mathrm{KO}_{2}+$ tempol $10 \mathrm{mg} / \mathrm{kg} ;{ }^{\# \#} p<0.05$ versus $\mathrm{KO}_{2}+$ tempol $30 \mathrm{mg} / \mathrm{kg}$ (ANOVA followed by Tukey's $t$-test)].

interaction. When there was a significant time versus treatment interaction, one-way ANOVA followed by Tukey's $t$ test was performed for each time. Statistical differences were considered to be significant at $p<0.05$.

\section{Results}

3.1. Tempol Inhibits $\mathrm{KO}_{2}$-Induced Hyperalgesia and Paw Edema. In the first experimental setting, a dose-response curve of potential analgesic and anti-inflammatory effects of tempol was investigated in $\mathrm{KO}_{2}$-induced paw inflammation. Mice were treated with 10,30 , and $100 \mathrm{mg} / \mathrm{kg}$ of tempol 40 min before the intraplantar injection of $\mathrm{KO}_{2}$, and mechanical hyperalgesia, thermal hyperalgesia, and paw edema were evaluated at indicated time points (Figure 1). $\mathrm{KO}_{2}$ induced mechanical hyperalgesia (Figure 1(a)) and thermal hyperalgesia (Figure 1(b)) and paw edema (Figure 1(c)) between 1 and $5 \mathrm{~h}$ after injection compared to the vehicle group, which were inhibited by tempol in a time- and dose-dependent manner. The dose of $10 \mathrm{mg} / \mathrm{kg}$ was inefficient to inhibit $\mathrm{KO}_{2}$-induced 
mechanical hyperalgesia (Figure 1(a)) but partially inhibited thermal hyperalgesia $(3 \mathrm{~h}$ ) (Figure $1(\mathrm{~b})$ ) and paw edema (3 and $5 \mathrm{~h}$ ) (Figure $1(\mathrm{c})$ ). Treatment with the dose of $30 \mathrm{mg} / \mathrm{kg}$ fully inhibited $\mathrm{KO}_{2}$-induced mechanical hyperalgesia and thermal hyperalgesia (Figures 1(a) and 1(b)) and inhibited $\mathrm{KO}_{2}$-induced paw edema at 3 and $5 \mathrm{~h}$ (Figure $1(\mathrm{c})$ ). The dose of $100 \mathrm{mg} / \mathrm{kg}$ completely inhibited mechanical hyperalgesia and thermal hyperalgesia and paw edema between 1 and $5 \mathrm{~h}$ (Figures 1(a)-1(c)) with statistical differences compared with the doses of 10 and $30 \mathrm{mg} / \mathrm{kg}$ in mechanical hyperalgesia ( $3 \mathrm{~h}$ ) and thermal hyperalgesia (1-5 h) (Figures 1(a) and 1(b)). Thus, the dose of $100 \mathrm{mg} / \mathrm{kg}$ of tempol was selected for the next series of experiments.

3.2. Tempol Inhibits $\mathrm{KO}_{2}$-Induced TNF $\alpha, I L-1 \beta$, and $I L$ 10 mRNA Expressions. Cytokines are classical molecules involved in the modulation of inflammatory pain [29]. Prohyperalgesic cytokines such as TNF $\alpha$ and IL-1 $\beta$ contribute to nociceptor neuron sensitization $[7,30]$ and cytokines such as IL-10 limit the development of hyperalgesia by inhibiting the production of hyperalgesic cytokines [31]. Therefore, the effect of tempol on $\mathrm{KO}_{2}$-induced cytokine production was evaluated. Mice were treated with tempol (100 mg/kg) $40 \mathrm{~min}$ before $\mathrm{KO}_{2}$ intraplantar injection and after $3 \mathrm{~h}$ paw skin and spinal cord samples were collected for TNF $\alpha$, IL- $1 \beta$, and IL10 mRNA expressions determination by RT-qPCR (Figure 2). $\mathrm{KO}_{2}$ induced an increase in TNF $\alpha$, IL- $1 \beta$, and IL-10 mRNA expressions in the paw skin (Figures 2(a), 2(c), and 2(e)) and spinal cord samples (Figures 2(b), 2(d), and 2(f)), which were significantly inhibited by tempol treatment. These data suggest that the analgesic effect of tempol is in part dependent on inhibiting cytokine production.

3.3. Tempol Inhibits the $\mathrm{KO}_{2}$-Induced COX-2 and preproET-1 $m R N A$ Expressions. COX-2 and endothelin-1 are involved in the molecular mechanism of nociceptor neuron sensitization in inflammatory pain. Cytokines induce the production of ET-1, which, in turn, induces the production of COX-2derived prostaglandin $\mathrm{E}_{2}\left(\mathrm{PGE}_{2}\right)[29,32,33]$. $\mathrm{PGE}_{2}$ sensitizes nociceptor sensory neurons via protein kinase A (PKA) phosphorylation of sodium channels [30]. Furthermore, $\mathrm{KO}_{2}$ induced pain depends on ET-1 [21, 22] and COX-2 [20]. Thus, it is conceivable to evaluate whether tempol inhibits $\mathrm{KO}_{2}$-induced mRNA expression of COX-2 and preproET-1. Mice received tempol (as for Figure 2) 40 min before $\mathrm{KO}_{2}$ intraplantar injection, and after additional $3 \mathrm{~h}$ paw skin and spinal cord samples were collected for COX-2 and preproET1 mRNA expressions determination by RT-qPCR (Figure 3). Treatment with tempol significantly inhibited $\mathrm{KO}_{2}$-induced COX-2 (Figures 3(a) and 3(b)) and preproET-1 (Figures 3(c) and $3(\mathrm{~d}))$ mRNA expressions in the paw skin and spinal cord samples. Thus, inhibiting $\mathrm{KO}_{2}$-induced mRNA expression of COX-2 and preproET-1 is a contributing mechanism to the analgesic effect of tempol.

3.4. Tempol Improves $\mathrm{KO}_{2}$-Induced Depletion of Antioxidant Capacity. The endogenous antioxidant system is an important mechanism to maintain tissue homeostasis through containment of oxidative stress [2]. In this sense, the implications of tempol upon antioxidant response in $\mathrm{KO}_{2}$-induced inflammatory pain should be determined. Mice were treated with tempol (as for Figure 2) $40 \mathrm{~min}$ before $\mathrm{KO}_{2}$ intraplantar injection, and after additional $3 \mathrm{~h}$ paw skin and spinal cord samples were collected for evaluation of antioxidant capacity by FRAP, ABTS, and GSH assays (Figure 4). $\mathrm{KO}_{2}$ induced endogenous antioxidant depletion in the paw skin and spinal cord as observed by reduction of FRAP (Figures 4(a) and 4(b)), ABTS (Figures 4(c) and 4(d)), and GSH (Figures 4(e) and $4(\mathrm{f}))$ assays. On the other hand, treatment with tempol restored the antioxidant capacity of paw skin and spinal cord samples (Figures 4(a)-4(f)). These data provide evidence that preserving the endogenous production of antioxidants is a contributing mechanism of tempol to inhibit $\mathrm{KO}_{2}$-induced inflammatory pain.

3.5. Tempol Inhibits $\mathrm{KO}_{2}$-Induced Oxidative Stress. Oxidative stress mediates inflammatory pain [2]. Therefore, to confirm the antioxidant effect of tempol in $\mathrm{KO}_{2}$-induced inflammatory pain, the next experiments assessed the mRNA expression of gp91 ${ }^{\text {phox }}$, a subunit of NADPH oxidase which catalyzes superoxide anion production during inflammation [28], and superoxide anion levels. Mice received tempol (as for Figure 2) $40 \mathrm{~min}$ before $\mathrm{KO}_{2}$ intraplantar injection, and after additional $3 \mathrm{~h}$ paw skin and spinal cord samples were collected for RT-qPCR determination of gp91 ${ }^{\text {phox }}$ mRNA expression and superoxide anion production (Figure 5). $\mathrm{KO}_{2}$ induced gp91 ${ }^{\text {phox }}$ mRNA expression and superoxide anion production were inhibited by tempol treatment in the paw skin (Figures 5(a) and 5(b)) and spinal cord (Figures 5(c) and $5(\mathrm{~d})$ ). The inhibition of $\mathrm{KO}_{2}$-induced gp91 ${ }^{\text {phox }}$ mRNA expression and its product, superoxide anion, demonstrate that tempol inhibits the production and system involved in the production of superoxide anion, therefore contributing to reducing oxidative stress.

3.6. Tempol Inhibits $\mathrm{KO}_{2}$-Induced Decrease of Nrf2 mRNA Expression. Other important pathways that control the deleterious impact of oxidative stress in tissues are mediated by the transcription factor $\mathrm{Nrf} 2 . \mathrm{KO}_{2}$ reduces $\mathrm{Nrf} 2$ mRNA expression and drugs that enhance Nrf2 mRNA expression inhibit $\mathrm{KO}_{2}$-induced pain [34]. Thus, the effect of tempol in $\mathrm{KO}_{2}$-induced reduction of $\mathrm{Nrf} 2$ mRNA expression was investigated. Mice were treated with tempol (as for Figure 2) $40 \mathrm{~min}$ before $\mathrm{KO}_{2}$ intraplantar injection, and after additional $3 \mathrm{~h}$ paw skin and spinal cord samples were collected for the determination of Nrf2 mRNA expression (Figure 6). $\mathrm{KO}_{2}$ significantly reduced $\mathrm{Nrf} 2 \mathrm{mRNA}$ expression in the paw skin and spinal cord compared to vehicle group. Tempol treatment prevented the $\mathrm{KO}_{2}$-induced reduction of Nrf2 mRNA expression levels (Figures 6(a) and 6(b)). This result suggests that tempol preserves the expression of an endogenous transcription factor involved in controlling $\mathrm{KO}_{2}$ induced oxidative stress and inflammatory pain.

3.7. Tempol Inhibits $\mathrm{KO}_{2}$-Induced Glial Cells Activation. Detection of painful stimuli at the periphery by primary 


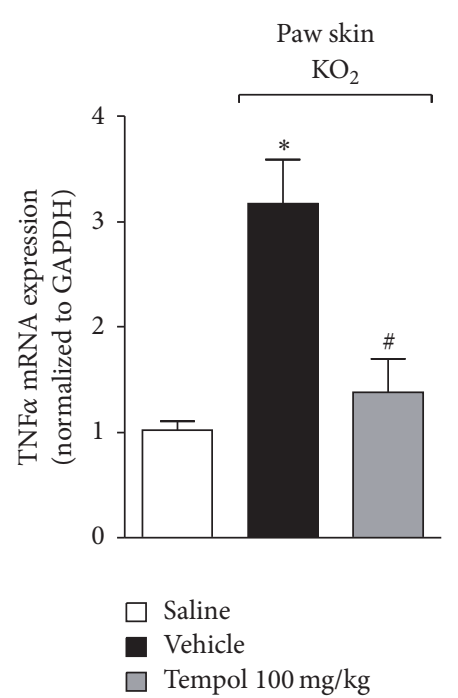

(a)
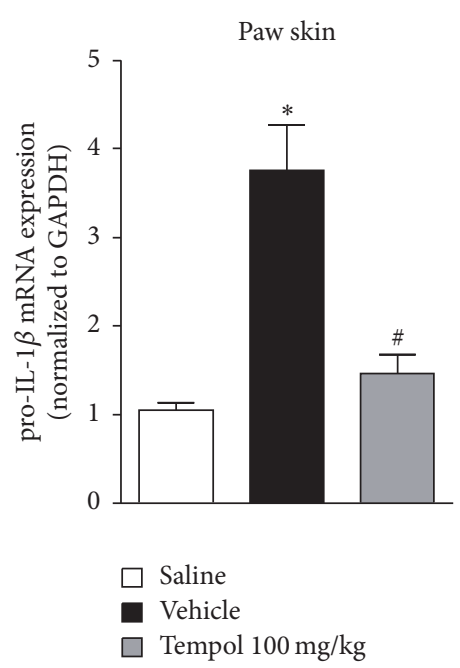

(c)

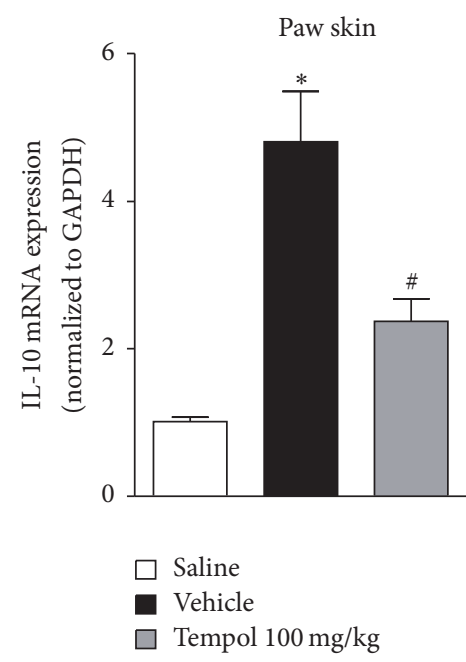

(e)

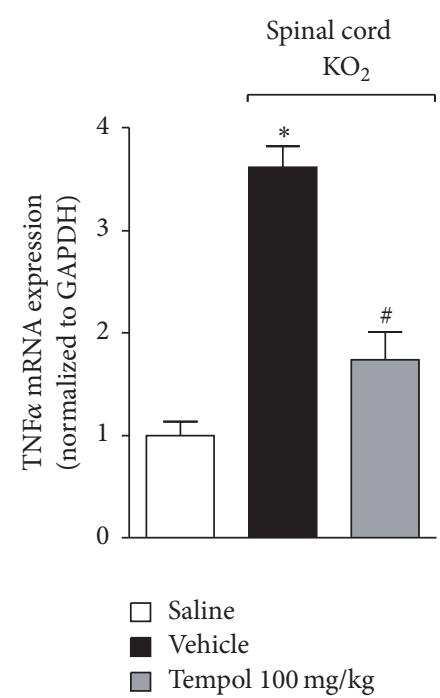

(b)

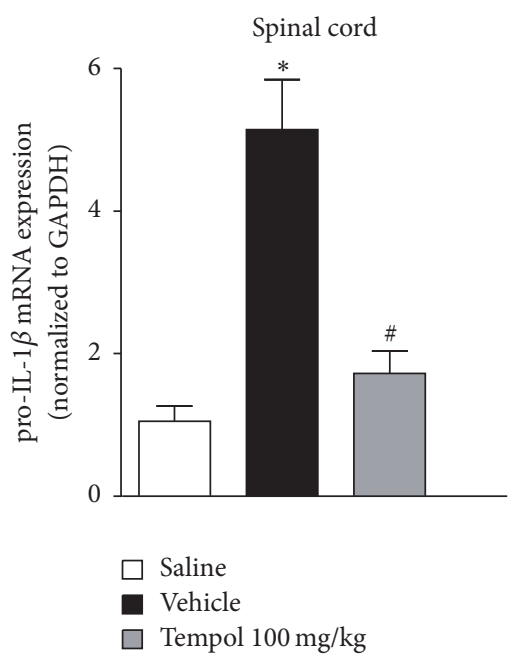

(d)

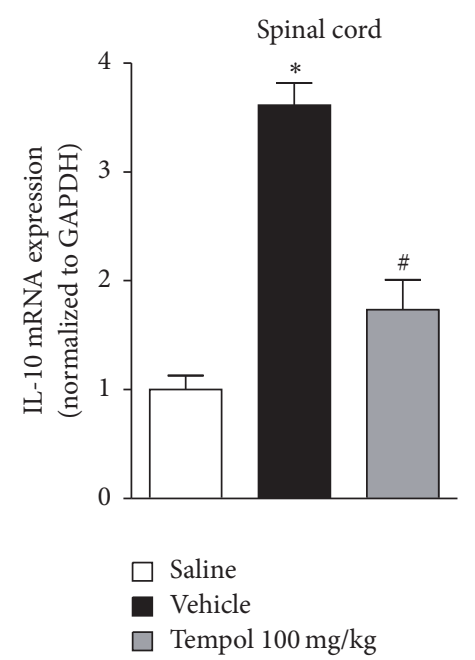

(f)

FIgURE 2: Tempol inhibits $\mathrm{KO}_{2}$-induced TNF $\alpha$, IL-1 $\beta$, and IL-10 mRNA expression in the paw skin and spinal cord. Mice were treated with tempol $(100 \mathrm{mg} / \mathrm{kg})$ or vehicle $40 \mathrm{~min}$ before $\mathrm{KO}_{2}$ intraplantar injection. Paw skin and spinal cord samples were collected $3 \mathrm{~h}$ after $\mathrm{KO}_{2}{ }^{-}$ stimulus and TNF $\alpha$ ((a) and (b)), IL-1 $\beta$ ((c) and (d)), and IL-10 ((e) and (f)) mRNA expressions were evaluated by RT-qPCR. Results were normalized using GAPDH as gene control and expressed as means \pm SEM $(n=6$ per group per experiment, representative of two separate experiments) [ ${ }^{*} p<0.05$ versus saline; ${ }^{*} p<0.05$ versus $\mathrm{KO}_{2}+$ vehicle (one-way ANOVA followed by Tukey's $t$-test)]. 


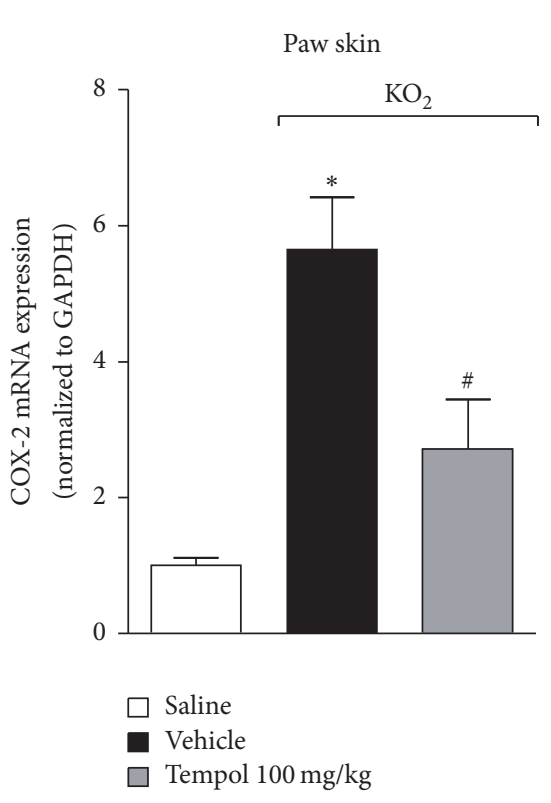

(a)

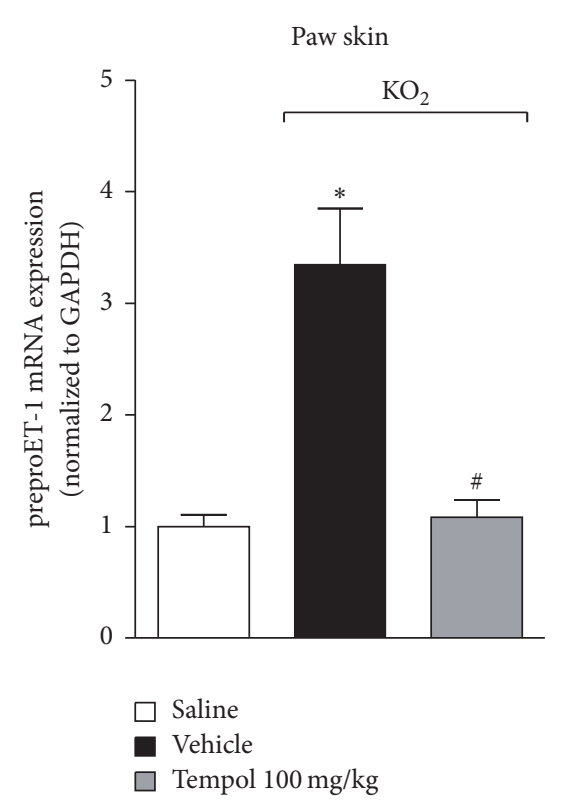

(c)

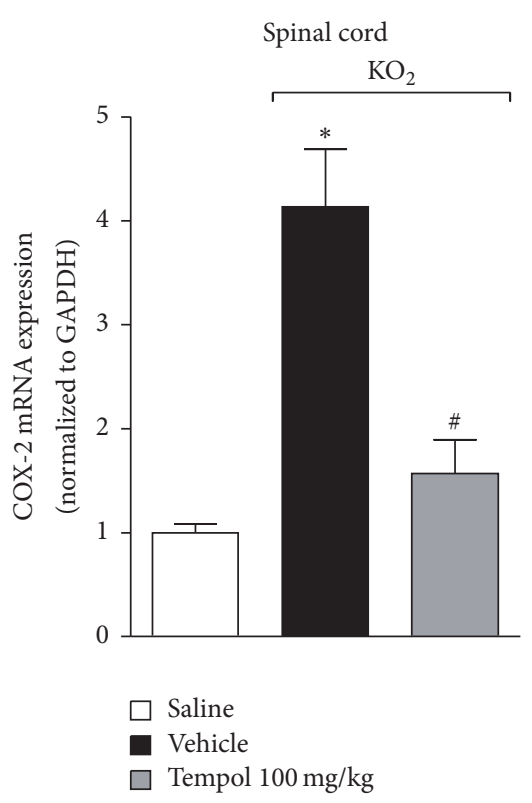

(b)

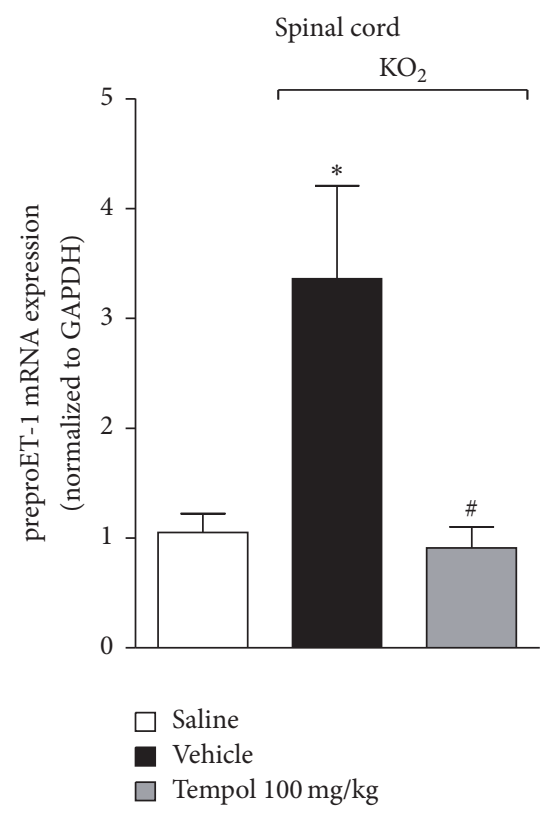

(d)

Figure 3: Tempol inhibits $\mathrm{KO}_{2}$-induced COX-2 and preproET-1 mRNA expressions in the paw skin and spinal cord. Mice were treated with tempol $(100 \mathrm{mg} / \mathrm{kg})$ or vehicle $40 \mathrm{~min}$ before $\mathrm{KO}_{2}$ intraplantar injection. Paw skin and spinal cord samples were collected $3 \mathrm{~h}$ after $\mathrm{KO}_{2}$ stimulus and COX-2 ((a) and (b)) and preproET-1 ((c) and (d)) mRNA expressions were evaluated by RT-qPCR. Results were normalized using GAPDH as gene control and expressed as means \pm SEM ( $n=6$ per group per experiment, representative of two separate experiments) $\left[{ }^{*} p<0.05\right.$ versus saline; ${ }^{\#} p<0.05$ versus $\mathrm{KO}_{2}+$ vehicle (one-way ANOVA followed by Tukey's $t$-test)].

sensory neurons initiates and propagates the nociceptive signaling to spinal cord sites, where glial cells are activated to produce several mediators that induce nociceptor sensitization and neuroinflammation $[30,35]$. Therefore, the mRNA expressions of glial cells activation markers were used to assess potential effect of tempol in inhibiting $\mathrm{KO}_{2}$-induced activation of spinal cord glial cells. Mice were treated with tempol (as for Figure 2) $40 \mathrm{~min}$ before $\mathrm{KO}_{2}$ intraplantar injection, and after additional $3 \mathrm{~h}$ spinal cord samples were collected for the determination of GFAP and Iba-1 mRNA expressions. GFAP and Iba-1 are markers of astrocytic and microglial activity, respectively (Figure 7 ). $\mathrm{KO}_{2}$ induced an increase of GFAP (Figure 7(a)) and Iba-1 (Figure 7(b)) mRNA expressions in the spinal cord, which was inhibited by tempol. These data indicate that tempol inhibits $\mathrm{KO}_{2}$-induced activation of glial cells in the spinal cord. 


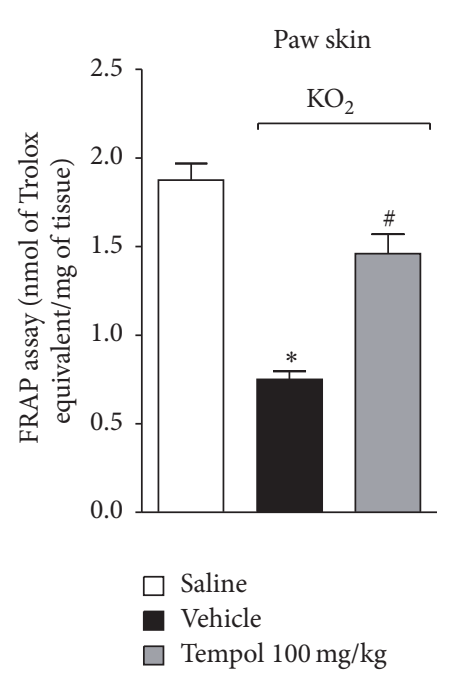

(a)

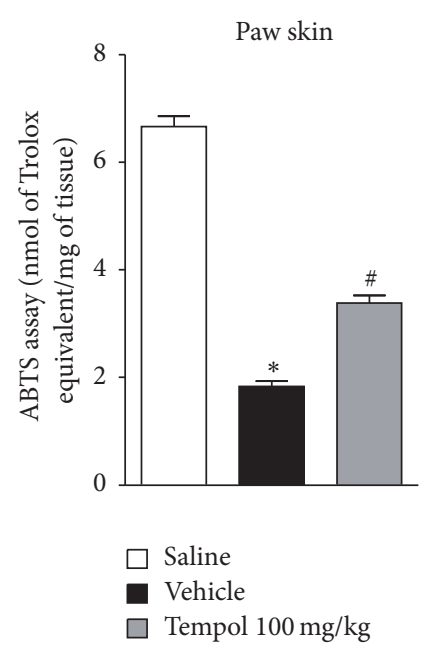

(c)

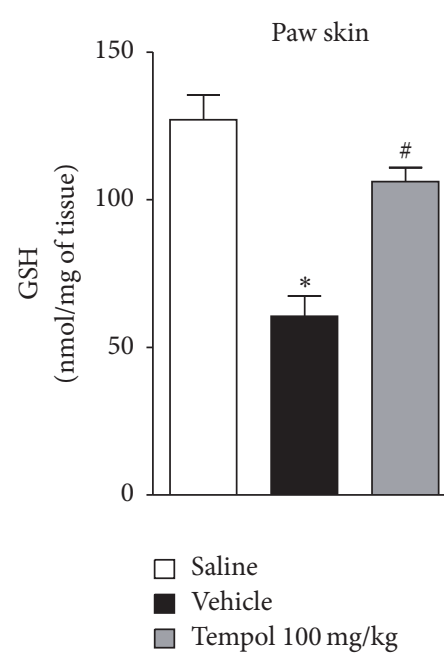

(e)

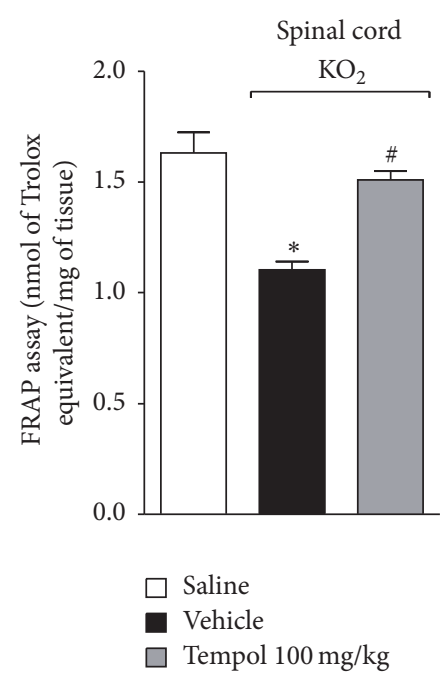

(b)

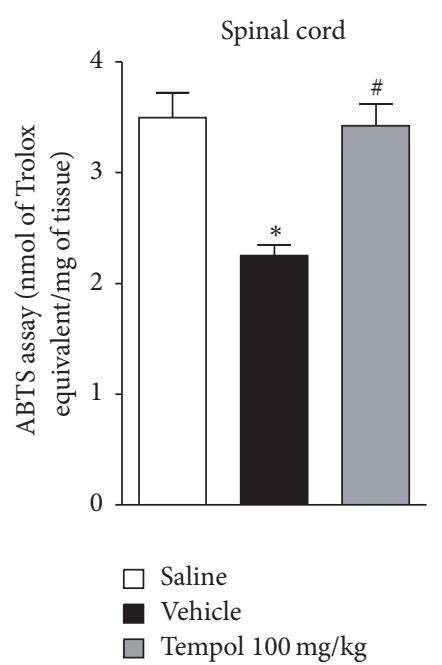

(d)

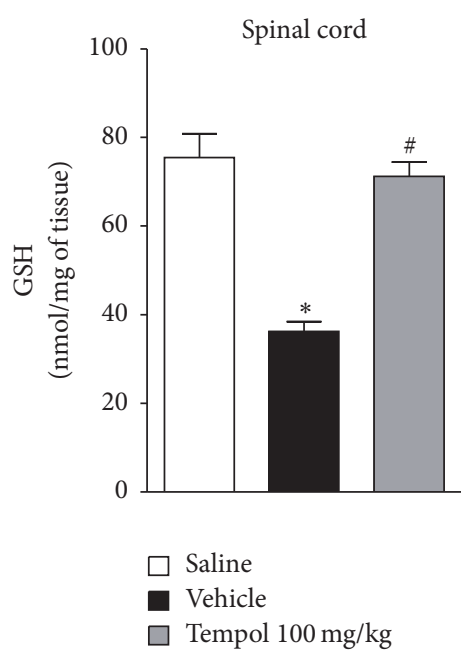

(f)

Figure 4: Tempol inhibits $\mathrm{KO}_{2}$-induced depletion of antioxidant capacity in the paw skin and spinal cord. Mice were treated with tempol $\left(100 \mathrm{mg} / \mathrm{kg}\right.$ ) or vehicle 40 min before $\mathrm{KO}_{2}$ intraplantar injection. Paw skin and spinal cord samples were collected $3 \mathrm{~h}$ after $\mathrm{KO}_{2}$-stimulus and the oxidant capacity was evaluated by FRAP ((a) and (b)), ABTS ((c) and (d)), and GSH ((e) and (f)) assays. Results are expressed as means \pm $\operatorname{SEM}\left(n=6\right.$ per group per experiment, representative of two separate experiments) $\left[{ }^{*} p<0.05\right.$ versus saline; ${ }^{\#} p<0.05$ versus $\mathrm{KO}_{2}+\mathrm{vehicle}$ (one-way ANOVA followed by Tukey's $t$-test)]. 


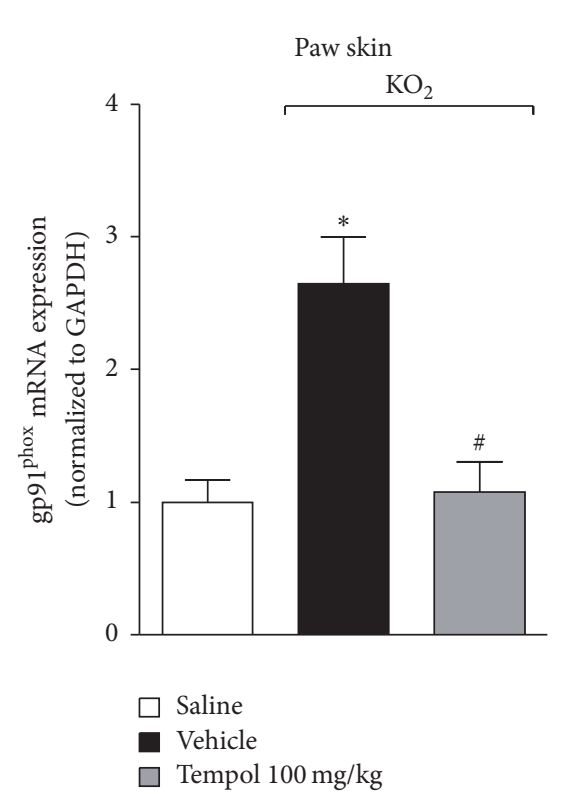

(a)

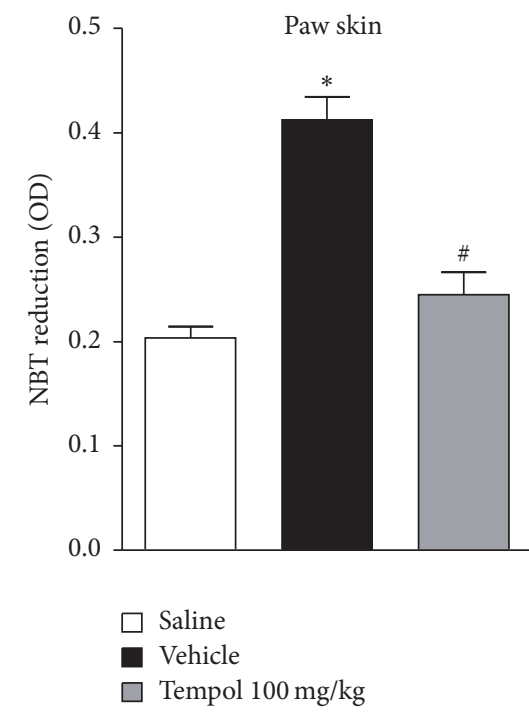

(c)

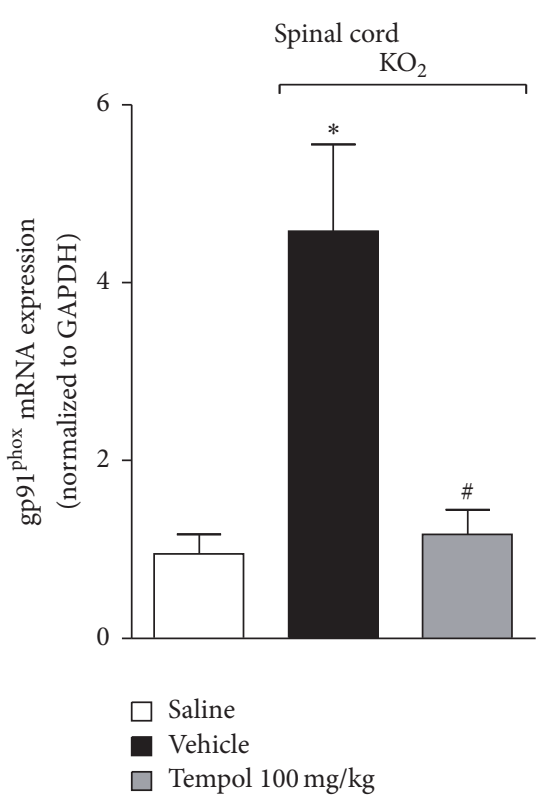

(b)

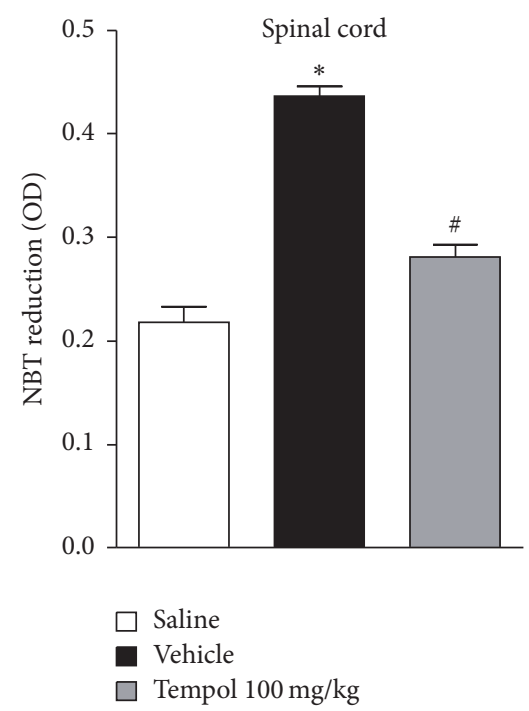

(d)

FIGURE 5: Tempol inhibits $\mathrm{KO}_{2}$-induced oxidative stress in the paw skin and spinal cord. Mice were treated with tempol (100 mg/kg) or vehicle 40 min before $\mathrm{KO}_{2}$ intraplantar injection. Paw skin and spinal cord samples were collected $3 \mathrm{~h}$ after $\mathrm{KO}_{2}$ injection to evaluate gp91 ${ }^{\text {phox }}$ mRNA expression ((a) and (b)) and NBT reduction (superoxide anion production assay, (c) and (d)) by qPCR and colorimetric assay, respectively. Results were normalized using GAPDH as gene control and expressed as means \pm SEM ( $n=6$ per group per experiment, representative of two separate experiments) [ ${ }^{*} p<0.05$ versus saline; ${ }^{\#} p<0.05$ versus $\mathrm{KO}_{2}+$ vehicle (one-way ANOVA followed by Tukey's $t$-test)].

3.8. Tempol Inhibits Carrageenan- and CFA-Induced Hyperalgesia. The ability of tempol to inhibit carrageenan- and CFAinduced mechanical hyperalgesia and thermal hyperalgesia was also tested considering that these are classical models of inflammatory hyperalgesia [23] (Figure 8). Mice were treated as described in the experimental protocol section. Tempol treatment inhibited carrageenan- (Figures 8(a) and 8(b)) and CFA- (Figures 8(c) and 8(d)) induced mechanical hyperalgesia and thermal hyperalgesia between 1 and $5 \mathrm{~h}$ and between 1 and 7 days, respectively. These results indicate that the analgesic effect of tempol is not limited to superoxide anion-triggered hyperalgesia, but it is also relevant in classical models of inflammatory pain such as carrageenan and CFA.

\section{Discussion}

Overproduction of superoxide anion has been implicated in excessive inflammatory response and pain by a mechanism in which superoxide anion nitrates manganese (Mn) SOD blocking its activity. As a consequence of this blockade, 


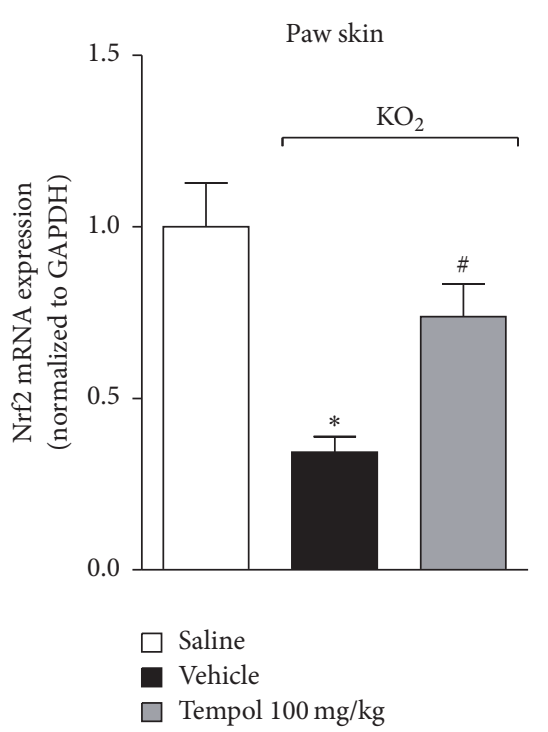

(a)

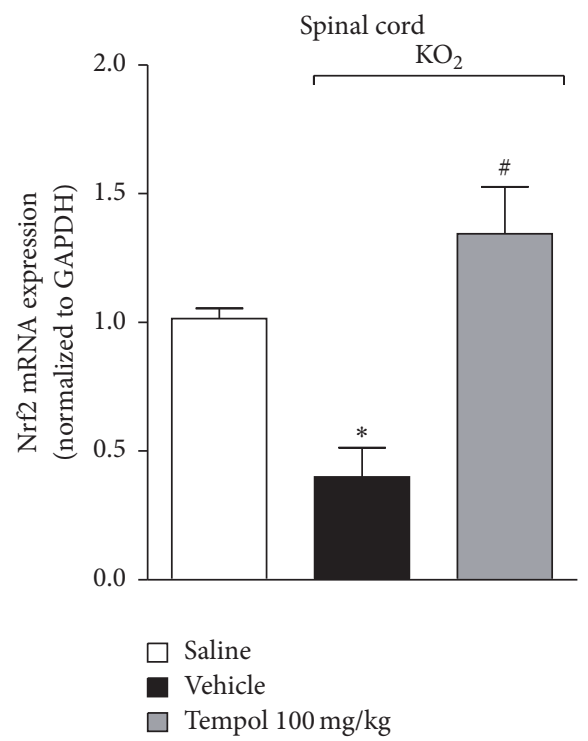

(b)

FIGURE 6: Tempol inhibits $\mathrm{KO}_{2}$-induced decrease of Nrf2 mRNA expression in the paw skin and spinal cord. Mice were treated with tempol $(100 \mathrm{mg} / \mathrm{kg})$ or vehicle $40 \mathrm{~min}$ before $\mathrm{KO}_{2}$ intraplantar injection. Paw skin and spinal cord samples were collected $3 \mathrm{~h}$ after $\mathrm{KO}_{2}$ injection and Nrf2 mRNA expression was evaluated by qPCR. Results were normalized using GAPDH as gene control and expressed as means \pm SEM ( $n=6$ per group per experiment, representative of two separate experiments) $\left[{ }^{*} p<0.05\right.$ versus saline; ${ }^{\#} p<0.05$ versus $\mathrm{KO}_{2}+$ vehicle (one-way ANOVA followed by Tukey's $t$-test)].

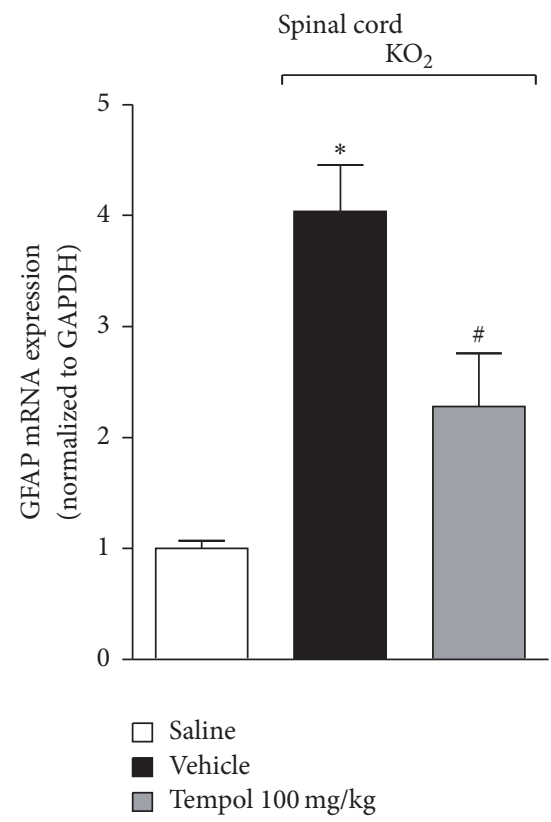

(a)

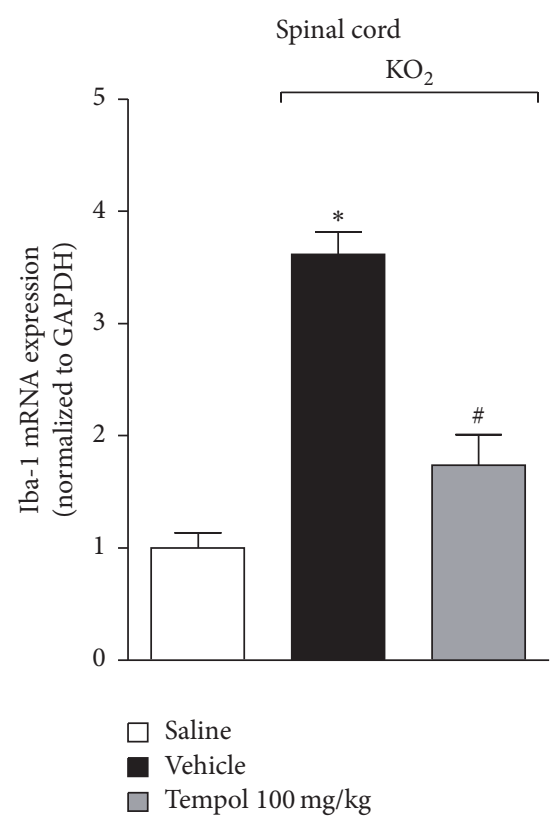

(b)

FIGURE 7: Tempol inhibits $\mathrm{KO}_{2}$-induced astrocytes and microglia activation in the spinal cord. Mice were treated with tempol (100 mg/kg) or vehicle 40 min before $\mathrm{KO}_{2}$ intraplantar injection. Spinal cord samples were collected $3 \mathrm{~h}$ after $\mathrm{KO}_{2}$ injection and GFAP (a) and Iba-1 (b) mRNA expressions were evaluated by RT-qPCR. Results were normalized using GAPDH as gene control and expressed as means \pm SEM ( $n=6$ per group per experiment, representative of two separate experiments) $\left[{ }^{*} p<0.05\right.$ versus saline; ${ }^{\#} p<0.05$ versus $\mathrm{KO}_{2}+$ vehicle (one-way ANOVA followed by Tukey's $t$-test)]. 


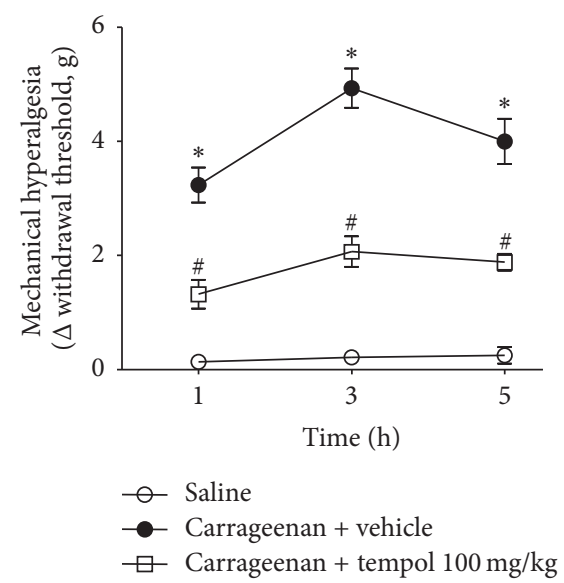

(a)

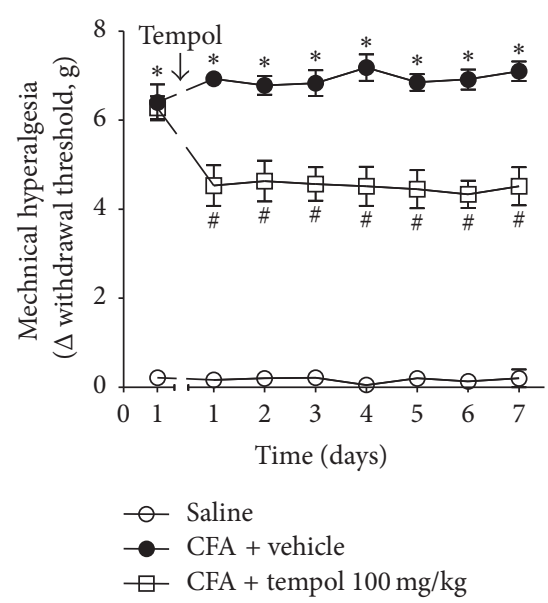

(c)

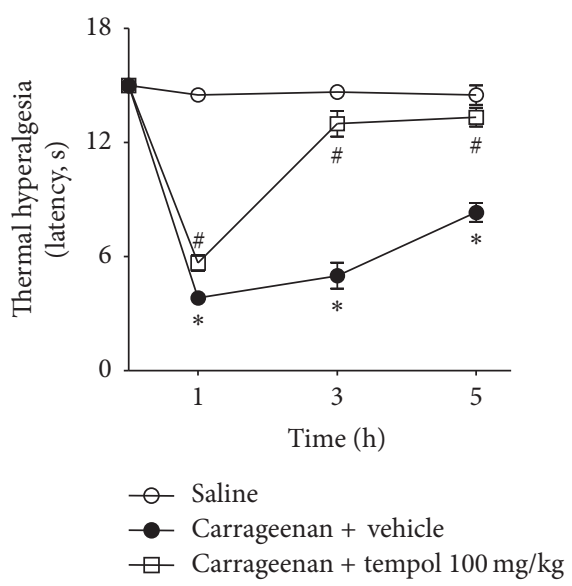

(b)

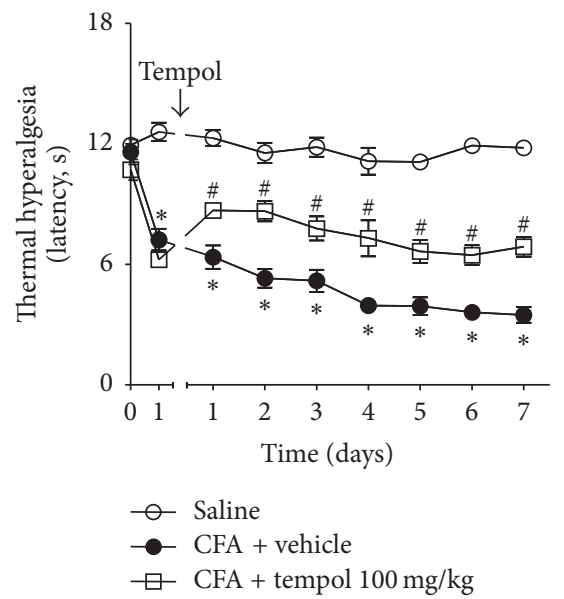

(d)

Figure 8: Tempol inhibits carrageenan and complete Freund's adjuvant- (CFA-) induced hyperalgesia. Mice were treated with tempol $(100 \mathrm{mg} / \mathrm{kg})$ or vehicle $40 \mathrm{~min}$ before carrageenan or CFA intraplantar injection. Nociceptive thresholds to mechanical and thermal stimuli were measured 1-5 h after carrageenan injection (panels (a) and (b), resp.) and 1-7 days after CFA injection (panels (c) and (d), resp.). Results are expressed as means \pm SEM $\left(n=6\right.$ per group per experiment, representative of two separate experiments) $\left[{ }^{*} p<0.05\right.$ versus saline; ${ }^{\#} p<0.05$ versus carrageenan + vehicle for panels (a)-(b) and versus CFA + vehicle for panels (c)-(d) (ANOVA followed by Tukey's $t$-test)].

there are persistent high levels of superoxide anion with deleterious effects on tissues leading to increased nociceptive transmission [1-4]. In the present study, the effect of the SOD mimetic agent tempol over $\mathrm{KO}_{2}$ (superoxide anion donor)-induced pain and inflammation was evaluated. Tempol inhibited $\mathrm{KO}_{2}$-induced pain and inflammation. These effects were accompanied by inhibition of production of several proinflammatory and prooxidant mediators. Therefore, tempol emerges as an interesting molecule to efficiently target inflammatory pain scenarios related to superoxide anion. In agreement, the analgesic effect of tempol was also observed in the carrageenan and CFA classic models of inflammation.

There seems to be a strong interaction between inflammatory signaling and the amplification of superoxide anion production and vice versa. For instance, Toll-like receptor (TLR)/interleukin-1 receptor-associated kinase (IRAK) signaling leads to a fast activation of NADPH oxidase resulting in superoxide anion production $[36,37]$. Superoxide anion mediates TLR4-induced nuclear factor $\kappa \mathrm{B}(\mathrm{NF}-\kappa \mathrm{B})$ activation. NF- $\kappa \mathrm{B}$ is considered a redox-sensitive transcription factor [38]. In fact, NF- $\kappa \mathrm{B}$ activation has been implicated in de novo superoxide anion production [38] and TLR4/myeloid differentiation primary response gene 88 (MyD88) activation induces inflammatory pain [39]. Cytokines such as TNF $\alpha$ and IL- $1 \beta$ can activate NADPH oxidase inducing superoxide anion production $[40,41]$, and TNF $\alpha /$ TNFR1 signaling mediates superoxide anion-triggered pain and oxidative stress and $\mathrm{TNF} \alpha$-induced hyperalgesia depends on superoxide anion [7]. In addition to proinflammatory cytokines, there is the participation of antiinflammatory cytokines. IL-10 is an antihyperalgesic cytokine in inflammatory, neuropathic, and cancer pain models [4244]. For instance, IL-10 deficiency increases superoxide anion production and NADPH oxidase activity demonstrating that IL-10 limits inflammation and hyperalgesia [31, 45].

Nociceptors express cytokine receptors enabling cytokines to activate these neurons [30]. During peripheral inflammation, resident cells such as macrophages and mast 
cells and recruited cells such as neutrophils converge for producing large amounts of mediators including TNF $\alpha$, IL$1 \beta$, and $\mathrm{PGE}_{2}$. These hyperalgesic molecules interact with their respective receptors in peripheral nerve terminals of primary nociceptive neurons triggering intracellular signaling pathways that lead to the opening of ion channels such as $\mathrm{Na}_{\mathrm{v}} 1.7, \mathrm{Na}_{\mathrm{v}} 1.8, \mathrm{Na}_{\mathrm{v}} 1.9$, transient receptor potential V1 (TRPV1), and TRPA1. The consequent depolarization and increased action potential generation and propagation in the peripheral sensory neuron toward central terminals result in hyperalgesia [30]. There is evidence that cytokines induce COX-2-dependent production of $\mathrm{PGE}_{2}$, which in turn sensitizes nociceptor neurons $[29,33]$. During prostaglandin production, COX-2 also produces superoxide anion, and superoxide anion induces COX-2 expression and activitydependent hyperalgesia $[21,38]$. Therefore, the inhibition of $\mathrm{KO}_{2}$-induced TNF $\alpha$, IL- $1 \beta$, and COX- 2 expressions by tempol is an important mechanism for inhibition of hyperalgesia. ET-1 is a hyperalgesic peptide [33], which mediates superoxide anion-induced pain, cytokine production, and oxidative stress $[21,22]$. The present data show that tempol inhibited peripheral and spinal cord superoxide anion-induced TNF $\alpha$, IL- $1 \beta$, COX-2, and preproET- 1 mRNA expressions, evidencing that tempol treatment reduces the production of a cascade of inflammatory molecules triggered by superoxide anion and that this mechanism might contribute to reducing superoxide anion-induced pain and inflammation.

It is also important to mention that superoxide anion activates terminal endings of nociceptive neurons through the redox-sensitive TRPA1 $[10,46]$ and reduces the threshold of nociceptive neurons through protein kinase (PK) CEmediated TRPV1 activation [47]. Superoxide anion can also directly activate nociceptive neurons to induce pain. Interestingly, neurotransmission seems to have a role in inducing superoxide anion production considering that glutamate triggers it [48]. The above data suggest that superoxide anion can induce direct and indirect effects in nociceptive transmission resulting in hyperalgesia via molecules such as cytokines, ET-1, and prostanoids [29].

Besides nitration of MnSOD, it is possible that superoxide anion induces its own production via NADPH oxidase. In fact, tempol reduced $\mathrm{KO}_{2}$-induced depletion of total antioxidant capacity and reduced the mRNA expression of the NADPH oxidase subunit gp $91^{\text {phox }}$ and its product superoxide anion. Importantly, the superoxide anion production assessed by NBT method was observed $3 \mathrm{~h}$ after $\mathrm{KO}_{2}$ injection. In saline solution, superoxide anion vanishes in up to $10 \mathrm{~min}$ [20]. Therefore, it is unlikely that the superoxide anion production at peripheral and spinal cord levels observed $3 \mathrm{~h}$ after $\mathrm{KO}_{2}$ injection reflected the superoxide anion that was peripherally injected but rather an endogenous superoxide anion that was produced in response to the inflammatory stimulus. In this sense, it is reasonable to consider that, in addition to the accumulation of superoxide anion levels by the inhibition of MnSOD [49], immune cells produce superoxide anion contributing to increasing its levels.

Tempol acts catalyzing superoxide anion, which would increase hydroxyl radical $\left({ }^{\circ} \mathrm{OH}\right)$ levels production from hydrogen peroxide $\left(\mathrm{H}_{2} \mathrm{O}_{2}\right)$. However, tempol protects cells from oxidative damage given that it also presents catalase-like activity, generating $\mathrm{H}_{2} \mathrm{O}$ and $\mathrm{O}_{2}$ from $\mathrm{H}_{2} \mathrm{O}_{2}$ and inhibiting - $\mathrm{OH}$ production $[12,17]$. These effects explain reduced lipid peroxidation achieved after tempol treatment in several experimental models $[15,17-19]$. Therefore, tempol is capable of modulating the activity of distinct components involved in the oxidative milieu, conferring additional protection to the tissues.

$\mathrm{Nrf} 2$ is a determinant transcription factor for the control of oxidative stress $[34,50] . \mathrm{KO}_{2}$ reduced $\mathrm{Nrf} 2$ mRNA expression in the paw skin and spinal cord, whereas tempol recovered its expression at both sites. Evidence indicates that Nrf2 can induce IL-10 and GSH production [50]. Herein, tempol did not increase IL-10 mRNA expression but rather reduced the mRNA expression of TNF $\alpha$ and IL- $1 \beta$, indicating that the mechanism of action of tempol does not include increasing IL-10 mRNA. Given that IL-10 is produced concomitantly to inflammatory cytokines to limit inflammation and pain [31], diminishing IL-10 mRNA expression can be a consequence of the tempol inhibition of superoxide anion-induced TNF $\alpha$ and IL- $1 \beta$ mRNA expressions. Tempol inhibited $\mathrm{KO}_{2}-$ induced depletion of GSH levels, which corroborates the tempol-induced increase of Nrf2 mRNA expression.

Inflammatory response at peripheral sites increases the nociceptive inputs at the spinal cord. Spinal glial cells respond to increased neurotransmission producing inflammatory cytokines and free radicals, including superoxide anion [29, 30]. Considering that tempol is cell-permeable and has the ability to cross the blood-spinal cord barrier due to its low molecular weight, it is possible that the antihyperalgesic effects of tempol reported here also reflect its activity at the spinal cord level, what needs to be further investigated. Nevertheless, the peripheral inhibition of nociceptive input by tempol also leads to a reduction of neurotransmission and spinal cord glial cells activation [51]. It is reasonable that the overall reduction of $\mathrm{KO}_{2}$-induced inflammation by tempol at peripheral sites resulted in reduced sensitization of spinal cord neurons. The spinal cord glial cell markers GFAP and Iba-1 reflect the activation of astrocytes and microglia, respectively. These cells contribute to hyperalgesia by producing nociceptive molecules such as cytokines which amplify nociceptive transmission [35]. $\mathrm{KO}_{2}$ increased GFAP and Iba1 mRNA expressions and peripheral treatment with tempol reduced their levels, suggesting that tempol inhibited spinal cord glial cells activation and consequently hyperalgesia.

Tempol inhibited carrageenan- and CFA-induced mechanical hyperalgesia and thermal hyperalgesia. These results support the applicability of tempol as an analgesic in other models of inflammation. Tempol is also an effective treatment in other pain conditions. For instance, tempol inhibits mechanical hyperalgesia and thermal hyperalgesia in models of neuropathic pain induced by CCI and chemotherapy [1416]. Therefore, these data support the potential of tempol as a promising analgesic and anti-inflammatory molecule for the treatment of both inflammatory and neuropathic pain.

In the present study, we demonstrate that peripheral injection of a superoxide anion donor induces the upregulation of the NADPH oxidase subunit gp91 ${ }^{\text {phox }}$ mRNA expression in the paw skin and spinal cord, which was reduced by 
the SOD mimetic agent tempol. Moreover, tempol reduced superoxide anion-induced TNF $\alpha$, IL- $1 \beta$, preproET-1, and COX-2 mRNA expressions in both paw skin and spinal cord. In fact, targeting these mediators in the paw skin and spinal cord with tempol or with other analgesics (present data, $[2,7,20-22])$ reduced superoxide anion-induced pain and inflammation. Finally, superoxide anion-triggered peripheral inflammation results in spinal cord activation of astrocytes and microglia, which was inhibited by tempol. This is important considering that long-term activation of these cells drives to a chronic pain state. Additionally, tempol inhibited not only superoxide anion-triggered inflammatory pain but also carrageenan- and CFA-induced inflammatory pain. Therefore, the present data suggest the importance of further investigation of tempol or tempol-like compounds in additional translational models of pain and/or chronic inflammation.

\section{Conflicts of Interest}

The authors declare that they have no conflicts of interest.

\section{Authors' Contributions}

This manuscript has been read and approved by all the authors, who contributed substantially to the work.

\section{Acknowledgments}

This work was supported by grants from Conselho Nacional de Desenvolvimento Científico e Tecnológico (CNPq), Coordenação de Aperfeiçoamento de Pessoal de Nível Superior (CAPES), Ministério da Ciência Tecnologia e Inovação (MCTI), Secretaria da Ciência, Tecnologia e Ensino Superior (SETI), Fundação Araucária, and Parana State Government, Brazil. Ana C. Zarpelon received a postdoctoral fellowship from CAPES/Fundação Araucária and Sergio M. Borghi received postdoctoral fellowships from CAPES and CNPq.

\section{References}

[1] Z.-Q. Wang, F. Porreca, S. Cuzzocrea et al., "A newly identified role for superoxide in inflammatory pain," Journal of Pharmacology and Experimental Therapeutics, vol. 309, no. 3, pp. 869878, 2004.

[2] D. Salvemini, J. W. Little, T. Doyle, and W. L. Neumann, "Roles of reactive oxygen and nitrogen species in pain," Free Radical Biology \& Medicine, vol. 51, no. 5, pp. 951-966, 2011.

[3] L. M. Henderson and J. B. Chappell, "NADPH oxidase of neutrophils," Biochimica et Biophysica Acta: Bioenergetics, vol. 1273, no. 2, pp. 87-107, 1996.

[4] C. Nathan, "Immunology: oxygen and the inflammatory cell," Nature, vol. 422, no. 6933, pp. 675-676, 2003.

[5] C. D. Sadik, N. D. Kim, and A. D. Luster, "Neutrophils cascading their way to inflammation," Trends in Immunology, vol. 32, no. 10, pp. 452-460, 2011.

[6] P. Niethammer, C. Grabher, A. T. Look, and T. J. Mitchison, "A tissue-scale gradient of hydrogen peroxide mediates rapid wound detection in zebrafish," Nature, vol. 459, no. 7249, pp. 996-999, 2009.

[7] F. Y. Yamacita-Borin, A. C. Zarpelon, F. A. Pinho-Ribeiro et al., "Superoxide anion-induced pain and inflammation depends on TNF $\alpha$ /TNFR1 signaling in mice," Neuroscience Letters, vol. 605, pp. 53-58, 2015.

[8] E. E. Ustinova and H. D. Schultz, "Activation of cardiac vagal afferents by oxygen-derived free radicals in rats," Circulation Research, vol. 74, no. 5, pp. 895-903, 1994.

[9] H. D. Schultz and E. E. Ustinova, "Capsaicin receptors mediate free radical-induced activation of cardiac afferent endings," Cardiovascular Research, vol. 38, no. 2, pp. 348-355, 1998.

[10] A. I. Caceres, M. Brackmann, M. D. Elia et al., "A sensory neuronal ion channel essential for airway inflammation and hyperreactivity in asthma," Proceedings of the National Academy of Sciences of the United States of America, vol. 106, no. 22, pp. 9099-9104, 2009.

[11] D. W. Laight, T. J. Andrews, A. I. Haj-Yehia, M. J. Carrier, and E. E. Änggård, "Microassay of superoxide anion scavenging activity in vitro," Environmental Toxicology and Pharmacology, vol. 3, no. 1, pp. 65-68, 1997.

[12] C. S. Wilcox, "Effects of tempol and redox-cycling nitroxides in models of oxidative stress," Pharmacology and Therapeutics, vol. 126, no. 2, pp. 119-145, 2010.

[13] M. M. Khattab, "TEMPOL, a membrane-permeable radical scavenger, attenuates peroxynitrite- and superoxide anionenhanced carrageenan-induced paw edema and hyperalgesia: a key role for superoxide anion," European Journal of Pharmacology, vol. 548, no. 1-3, pp. 167-173, 2006.

[14] M. Tal, "A novel antioxidant alleviates heat hyperalgesia in rats with an experimental painful peripheral neuropathy," NeuroReport, vol. 7, no. 8, pp. 1382-1384, 1996.

[15] B. Zhao, Y. Pan, Z. Wang, Y. Tan, and X. Song, "Intrathecal administration of tempol reduces chronic constriction injuryinduced neuropathic pain in rats by increasing SOD activity and inhibiting NGF expression," Cellular and Molecular Neurobiology, vol. 36, no. 6, pp. 893-906, 2016.

[16] H. K. Kim, S. H. Hwang, and S. Abdi, "Tempol ameliorates and prevents mechanical hyperalgesia in a rat model of chemotehrapy-induced neuropathic pain," Frontiers in Pharmacology, vol. 7, p. 532, 2016.

[17] M. M. Abouzied, H. M. Eltahir, A. Taye, and M. S. Abdelrahman, "Experimental evidence for the therapeutic potential of tempol in the treatment of acute liver injury," Molecular and Cellular Biochemistry, vol. 411, no. 1-2, pp. 107-115, 2016.

[18] M. R. Ali, A. M. Abo-Youssef, B. A. Messiha, and M. M. Khattab, "Tempol and perindopril protects against lipopolysaccharideinduced cognition impairment and amyloidogenesis by modulating brain-derived neurotropic factor, neuroinflammation and oxido-nitrosative stress," Naunyn-Schmiedeberg's Archives of Pharmacology, vol. 389, no. 6, pp. 637-656, 2016.

[19] U. A. Nilsson, L. I. Olsson, G. Carlin, and A. C. BylundFellenius, "Inhibition of lipid peroxidation by spin labels," Journal of Biological Chemistry, vol. 264, no. 19, pp. 11131-11135, 1898.

[20] N. A. Maioli, A. C. Zarpelon, S. S. Mizokami et al., "The superoxide anion donor, potassium superoxide, induces pain and inflammation in mice through production of reactive oxygen species and cyclooxygenase-2," Brazilian Journal of Medical and Biological Research, vol. 48, no. 4, pp. 321-331, 2015.

[21] K. G. Serafim, S. A. Navarro, A. C. Zarpelonet, and al. Bosentan, "Bosentan, a mixed endothelin receptor antagonist, inhibits 
superoxide anion-induced pain and inflammation in mice," Naunyn-Schmiedeberg's Archives of Pharmacology, vol. 388, no. 11, pp. 1211-1221, 2015.

[22] V. Fattori, K. G. Serafim, A. C. Zarpelon et al., "Differential regulation of oxidative stress and cytokine production by endothelin ETA and ETB receptors in superoxide anioninduced inflammation and pain in mice," Journal of Drug Targeting, vol. 25, no. 3, pp. 264-274, 2017.

[23] S. M. Borghi, T. T. Carvalho, L. Staurengo-Ferrari et al., "Vitexin inhibits inflammatory pain in mice by targeting TRPV1, oxidative stress, and cytokines," Journal of Natural Products, vol. 76, no. 6, pp. 1141-1146, 2013.

[24] T. M. Cunha, W. A. Verri Jr., G. G. Vivancos et al., "An electronic pressure-meter nociception paw test for mice," Brazilian Journal of Medical and Biological Research, vol. 37, no. 3, pp. 401-407, 2004.

[25] S. A. Navarro, K. G. Serafim, S. S. Mizokami, M. S. Hohmann, R. Casagrande, and W. A. Verri Jr., "Analgesic activity of piracetam: effect on cytokine production and oxidative stress," Pharmacology Biochemistry and Behavavior, vol. 105, pp. 183192, 2013.

[26] V. Katalinic, D. Modun, I. Music, and M. Boban, "Gender differences in antioxidant capacity of rat tissues determined by 2,2' -azinobis (3-ethylbenzothiazoline 6-sulfonate; ABTS) and ferric reducing antioxidant power (FRAP) assays," Comparative Biochemistry and Physiology Part C: Toxicology \& Pharmacology, vol. 140, no. 1, pp. 47-52, 2005.

[27] A. L. M. Ivan, M. Z. Campanini, R. M. Martinez et al., "Pyrrolidine dithiocarbamate inhibits UVB-induced skin inflammation and oxidative stress in hairless mice and exhibits antioxidant activity in vitro," Journal of Photochemistry and Photobiology B: Biology, vol. 138, pp. 124-133, 2014.

[28] M. S. N. Hohmann, R. D. R. Cardoso, F. A. Pinho-Ribeiro et al., "5-Lipoxygenase deficiency reduces acetaminophen-induced hepatotoxicity and lethality," BioMed Research International, vol. 2013, Article ID 627046, 13 pages, 2013.

[29] W. A. Verri Jr., T. M. Cunha, C. A. Parada, S. Poole, F. Q. Cunha, and S. H. Ferreira, "Hypernociceptive role of cytokines and chemokines: targets for analgesic drug development?" Pharmacology \& Therapeutics, vol. 112, no. 1, pp. 116-138, 2006.

[30] F. A. Pinho-Ribeiro, W. A. Verri Jr., and I. M. Chiu, "Nociceptor sensory neuron-immune interactions in pain and inflammation," Trends in Immunology, vol. 38, no. 1, pp. 5-19, 2017.

[31] S. M. Borghi, F. A. Pinho-Ribeiro, A. C. Zarpelon et al., "Interleukin-10 limits intense acute swimming-induced muscle mechanical hyperalgesia in mice," Experimental Physiology, vol. 100, no. 5, pp. 531-544, 2015.

[32] W. A. Verri Jr., T. M. Cunha, C. A. Parada et al., "Antigeninduced inflammatory mechanical hypernociception in mice is mediated by IL-18," Brain, Behavior, and Immunity, vol. 21, no. 5, pp. 535-543, 2007.

[33] W. A. Verri Jr., A. T. G. Guerrero, S. Y. Fukada et al., "IL-33 mediates antigen-induced cutaneous and articular hypernociception in mice," Proceedings of the National Academy of Sciences of the United States of America, vol. 105, no. 7, pp. 2723-2728, 2008.

[34] M. F. Manchope, C. Calixto-Campos, L. Coelho-Silva et al., "Naringenin inhibits superoxide anion-induced inflammatory pain: role of oxidative stress, cytokines, Nrf2 and the NOcGMP-PKG-KATP channel signaling pathway," PLoS ONE, vol. 11, no. 4, Article ID e0153015, 2016.
[35] A. C. Zarpelon, F. C. Rodrigues, A. H. Lopes et al., "Spinal cord oligodendrocyte-derived alarmin IL-33 mediates neuropathic pain," FASEB Journal, vol. 30, no. 1, pp. 54-65, 2016.

[36] S. Pacquelet, J. L. Johnson, B. A. Ellis et al., "Cross-talk between IRAK-4 and the NADPH oxidase," Biochemical Journal, vol. 403, no. 3, pp. 451-461, 2007.

[37] U. Maitra, N. Singh, L. Gan, L. Ringwood, and L. Li, "IRAK1 contributes to lipopolysaccharide-induced reactive oxygen species generation in macrophages by inducing NOX-1 transcription and Racl activation and suppressing the expression of antioxidative enzymes," Journal of Biological Chemistry, vol. 284, no. 51, pp. 35403-35411, 2009.

[38] M. M. Ndengele, C. Muscoli, Z. Q. Wang, T. M. Doyle, G. M. Matuschak, and D. Salvemini, "Superoxide potentiates $\mathrm{NF}-\kappa \mathrm{B}$ activation and modulates endotoxin-induced cytokine production in alveolar macrophages," Shock, vol. 23, no. 2, pp. 186-193, 2005.

[39] I. L. Calil, A. C. Zarpelon, A. T. G. Guerrero et al., "Lipopolysaccharide induces inflammatory hyperalgesia triggering a TLR4/MyD88-dependent cytokine cascade in the mice paw," PLoS ONE, vol. 9, no. 3, Article ID e90013, 2014.

[40] L. E. Kilpatrick, S. Sun, H. Li, T. C. Vary, and H. M. Korchak, "Regulation of TNF-induced oxygen radical production in human neutrophils: role of $\delta$-PKC," Journal of Leukocyte Biology, vol. 87, no. 1, pp. 153-164, 2010.

[41] F. Jiménez-Altayó, A. M. Briones, J. Giraldo, A. M. Planas, M. Salaices, and E. Vila, "Increased superoxide anion production by interleukin- $1 \beta$ impairs nitric oxide-mediated relaxation in resistance arteries," Journal of Pharmacology and Experimental Therapeutics, vol. 316, no. 1, pp. 42-52, 2006.

[42] S. Poole, F. Q. Cunha, S. Selkirk, B. B. Lorenzetti, and S. H. Ferreira, "Cytokine-mediated inflammatory hyperalgesia limited by interleukin-10," British Journal of Pharmacology, vol. 115, no. 4, pp. 684-688, 1995.

[43] E. D. Milligan, E. M. Sloane, S. J. Langer et al., "Controlling neurophatic pain by adeno-associated virus driven production of the anti-inflammatory cytokine, interleukin-10," Molecular Pain, vol. 1, article 9, 2005.

[44] W. M. Kim, C. W. Jeong, S. H. Lee, Y. O. Kim, J. H. Cui, and M. H. Yoon, "The intrathecally administered kappa-2 opioid agonist gr89696 and interleukin-10 attenuate bone cancer-induced pain through synergistic interaction," Anesthesia and Analgesia, vol. 113, no. 4, pp. 934-940, 2011.

[45] S. Koriauli, N. Natsvlishvili, T. Barbakdze, and D. Mikeladze, "Knockdown of interleukin-10 induces the redistribution of sigma-1 receptor and increases the glutamate-dependent NADPH-oxidase activity in mouse brain neurons," Biological Research, vol. 48, p. 55, 2015.

[46] B. F. Bessac, M. Sivula, C. A. von Hehn, J. Escalera, L. Cohn, and S.-E. Jordt, "TRPA1 is a major oxidant sensor in murine airway sensory neurons," Journal of Clinical Investigation, vol. 118, no. 5, pp. 1899-1910, 2008.

[47] K. Susankova, K. Tousova, L. Vyklicky, J. Teisinger, and V. Vlachova, "Reducing and oxidizing agents sensitize heat-activated vanilloid receptor (TRPV1) current," Molecular Pharmacology, vol. 70, no. 1, pp. 383-394, 2006.

[48] C. Muscoli, V. Mollace, J. Wheatley et al., "Superoxidemediated nitration of spinal manganese superoxide dismutase: a novel pathway in N-methyl-D-aspartate-mediated hyperalgesia," Pain, vol. 111, no. 1-2, pp. 96-103, 2004. 
[49] D. Salvemini, D. P. Riley, and S. Cuzzocrea, "SOD mimetics are coming of age," Nature Reviews Drug Discovery, vol. 1, no. 5, pp. 367-374, 2002.

[50] S. M. Borghi, F. A. Pinho-Ribeiro, V. Fattori et al., "Quercetin inhibits peripheral and spinal cord nociceptive mechanism to reduce intense acute swimming-induced muscle pain in mice," PLoS ONE, vol. 11, no. 9, Article ID e0162267, 2016.

[51] R. R. Ji, T. Kohno, K. A. Moore, and C. J. Woolf, "Central sensitization and LTP: do pain and memory share similar mechanisms?" Trends in Neurosciences, vol. 26, no. 12, pp. 696705, 2003. 

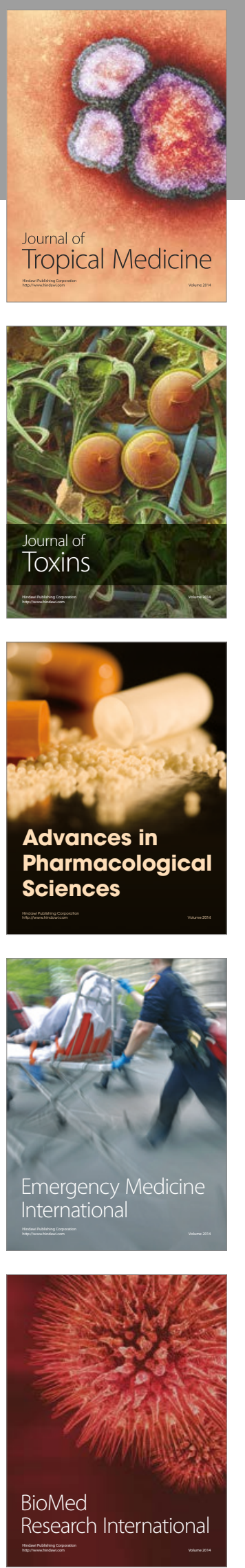
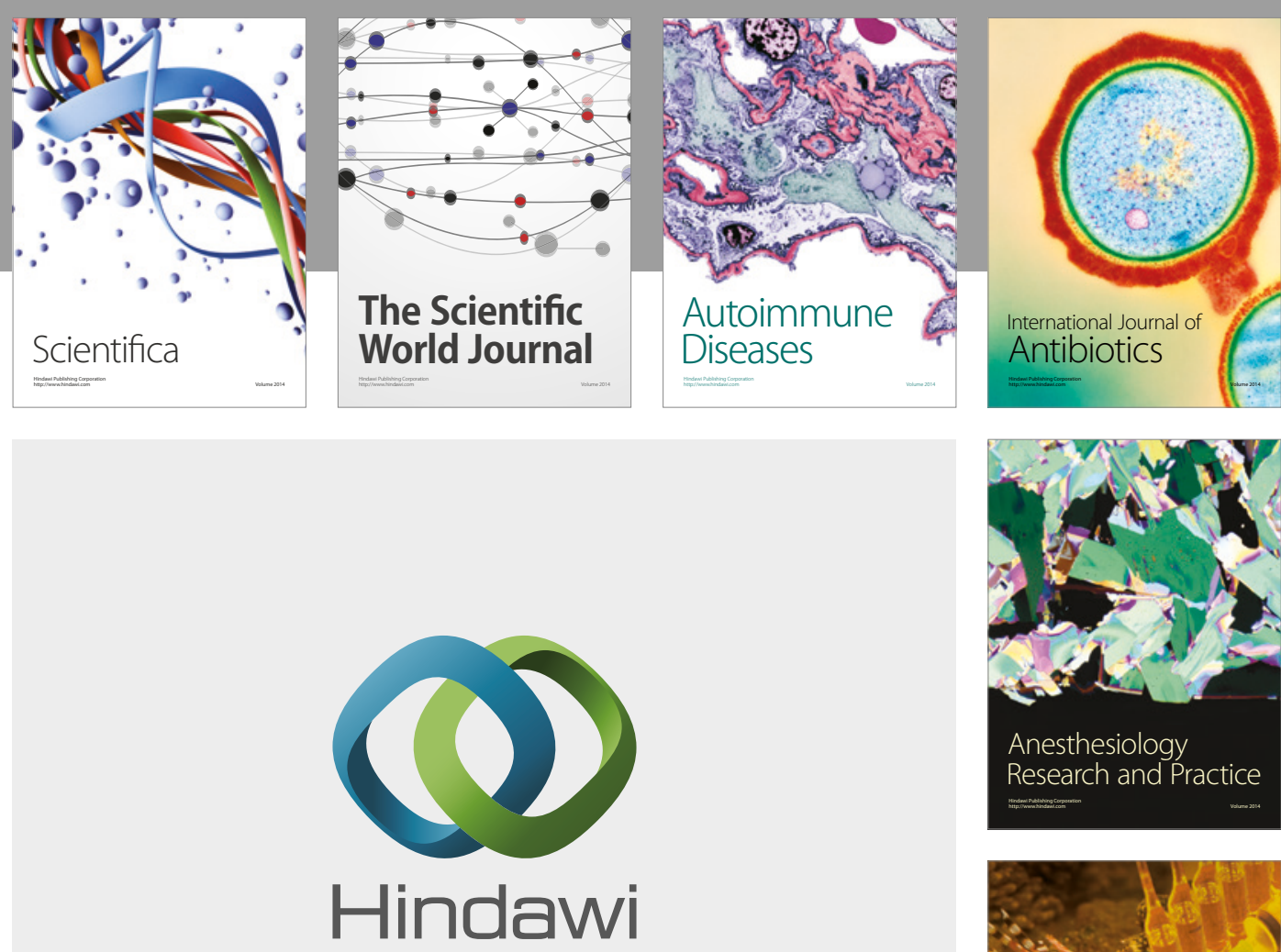

Submit your manuscripts at

https://www.hindawi.com
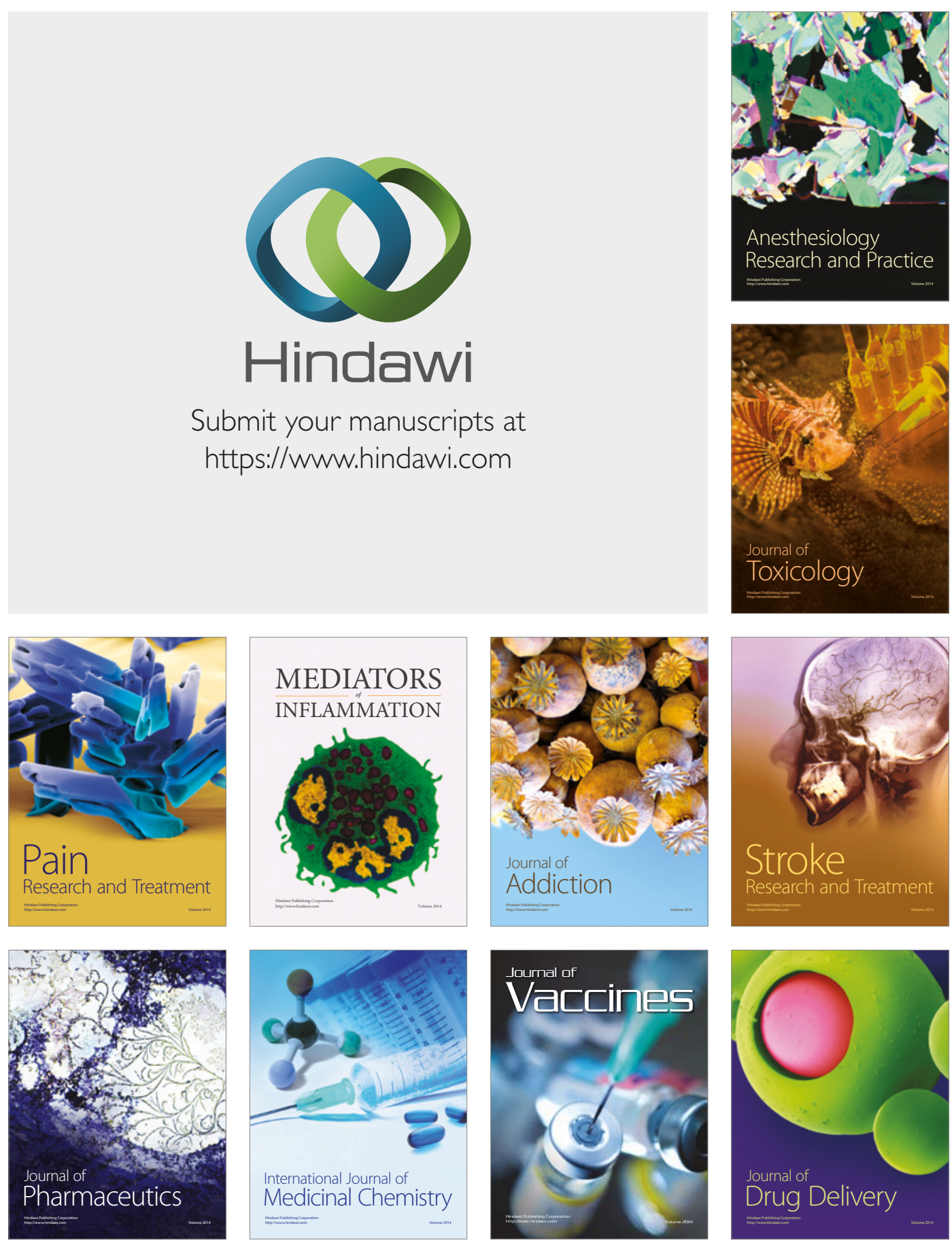